\title{
Crystallinity of FRCM/GPM with High PB through Microbial Growth
}

\author{
Sourav Kumar Das ${ }^{*}$, Bulbul Ahmed², Rony Mia ${ }^{3,4}$, Abu Bakar5, Injamam Ul Huq6, \\ Dan Xie ${ }^{1}$
}

${ }^{1}$ Biomedical Research Lab, Wuhan Textile University, Wuhan, China

${ }^{2}$ Department of Textile, Apparel \& Merchandising, Louisiana State University, Baton Rouge, USA

${ }^{3}$ College of Chemistry \& Chemical Engineering, Wuhan Textile University, Wuhan, China

${ }^{4}$ Department of Textile Engineering, National Institute of Textile Engineering \& Research (NITER), Dhaka, Bangladesh

${ }^{5}$ School of Textile Science and Engineering, Wuhan Textile University, Wuhan, China

${ }^{6}$ School of Material Science and Engineering, Wuhan Textile University, Wuhan, China

Email: ${ }^{*}$ sourav.biomedical@outlook.com

How to cite this paper: Das, S.K., Ahmed, B., Mia, R., Bakar, A., Huq, I.U. and Xie, D. (2020) Crystallinity of FRCM/GPM with High PB through Microbial Growth. Advances in Nanoparticles, 9, 81-116. https://doi.org/10.4236/anp.2020.94006

Received: September 17, 2020

Accepted: October 9, 2020

Published: October 12, 2020

Copyright $\odot 2020$ by author(s) and Scientific Research Publishing Inc. This work is licensed under the Creative Commons Attribution International License (CC BY 4.0).

http://creativecommons.org/licenses/by/4.0/

\begin{abstract}
Fiber reinforced composite (FRC) requires a process of grinding, mixing and compounding natural fibers from cellulosic waste streams into a polymer matrix that creates a high-strength fiber composite. In this situation, the specified waste or base raw materials used are the waste thermoplastics and different types of cellulosic waste including rice husk and saw dust. FRC is a high-performance fiber composite achieved and made possible through a proprietary molecular re-engineering process by interlinking cellulosic fiber molecules with resins in the FRC material matrix, resulting in a product of exceptional structural properties. In this feat of molecular re-engineering, selected physical and structural properties of wood are effectively cloned and obtained in the FRC component, in addition to other essential qualities in order to produce superior performance properties to conventional wood. The dynamic characteristics of composite structures are largely extracted from the reinforcing of fibres. The fiber, held in place by the matrix resin, contributes to tensile strength in a composite, enhancing the performance properties in the final part, such as strength and rigidity, while minimizing weight. The advantages of composite materials always beat down their disadvantages. In this analysis, we tried to find out FRC advance manufacturing, recycling technology and future perspective for mankind and next generation development. This research will bring a new horizon for future science with FRC technology and every aspect of modern science which will bring a stable dimensional stability by recycling process with minimizing waste for environment and next generation science.
\end{abstract}




\section{Keywords}

Reinforced Composite, Advanced Manufacturing, Recycling Process, NGS, Crystalline, Polymeric Bonds

\section{Introduction}

Fiber reinforced composite materials assume a significant job in the technology today through the structure and assembling of cutting edge materials equipped for accomplishing higher solidness/thickness and quality/thickness proportions. Of specific significance is the issue of harm inception and development in fiber-fortified metal framework composite plates. In spite of the fact that the writing is wealthy in new improvements in the composite materials innovation, it needs hugely a predictable examination of harm systems in composite materials. During the previous two decades, specialists have been utilizing micromechanical strategies in the investigation of composite materials. The upsides of utilizing such techniques are that nearby impacts can be represented and distinctive harm components can be distinguished [1]. Composite materials comprise of at least two microconstituents that vary in structure and compound sythesis and which are insoluble in one another. Be that as it may, numerous composite materials are made out of just two stages: one named the framework, which is consistent and encompasses the other stage, frequently named the scattered stage. The goal of having at least two constituents is to exploit the unrivaled properties of the two materials without settling on the shortcoming of either of the two materials without settling on the shortcoming of either [1]. In a fiber fortified composite, the strands convey the heft of the heap and the framework fills in as a mode for the exchange of the heap. The network can be metal, polymer, or fired. The filaments similarly can be metal, fired, glass or polymers. A portion of the upsides of composites is high explicit quality, high explicit solidness or modulus, great measurement soundness, an abnormal mix of properties not effectively possible with amalgams, and so forth [2]. Surface completion assumes a significant job in numerous territories and is a factor critical in the assessment of machining precision. Albeit numerous elements influence the surface state of a machined part, cutting boundaries, for example, speed, feed, profundity of cut, and apparatus nose span affect the surface harshness for a given machine instrument and workpiece set-up. The utilization of fiber-fortified composite materials (FRCM) in industry has developed significantly as of late because of a few attractive properties that these materials have. Be that as it may, different characteristics inalienable in these materials, for example, anisotropy and weakness, are hindering both structure and assembling applications. In particular, for gap age procedures, harm marvels, for example, spalling, delamination, edge chipping and split development, are an aftereffect of the previously mentioned attributes of these materials. A few opening creation forms, including 
ordinary boring, ultrasonic penetrating, laser-pillar boring, water-stream boring, and so on, have been proposed for an assortment of monetary and quality reasons, however traditional boring is as yet the most broadly utilized strategy in industry today [3]. As of late, there has been an expanding enthusiasm for the investigation of keen or astute structures. Actuators and sensors are two key segments in these structures and piezoelectric composite is one of the dynamic materials which is maybe most broadly utilized as actuators and sensors. As a rule, piezoelectric composite materials are thought to be homogenous with successful electro-flexible properties which are subject to their constituent properties and microstructural geometry. So as to tailor a piezoelectric composite to the particular prerequisites of its job in a shrewd structure, it is important to build up a proficient logical model to foresee its viable electro elastic properties, and in this way to examine the impacts of the composite constituent properties and microstructural geometry on the general composite properties [4]. Composite cylinders can be strengthened with nonstop filaments. At the point when such tubes are exposed to pulverizing loads, the reaction is mind boggling and relies upon collaboration between the various systems that control the devastating procedure. The methods of pounding and their controlling systems are portrayed. Additionally, the subsequent squashing procedure and its productivity are tended to [5]. Boring is one of the major machining tasks which are as of now did on fiber-fortified composite materials. There are common place issues experienced when penetrating fiber-strengthened composites. These issues incorporate the delamination of the composites, quick instrument wear, fiber pullout, nearness of fine chip [6]. One of the deterrents confronting FRC material use is an absence of data with respect to the impact of plan boundaries on the mechanical presentation of a prosthesis. Engineering composite creators have figured out how to control mechanical properties in FRC structures by changing fiber direction, fiber content, and geometry, commonly alluded to as cross-sectional course of action or design. The greater part of dental fiber-strengthened composite (FRC) materials are manufactured utilizing hand lay-up forms, wherein the expert may decide the mechanical properties of the conclusive reclamation by the manner in which the composite constituents are organized in the last structure [7]. Improvement of the tar pre-impregnated FRC frameworks has prompted the expanded use of FRCs in the manufacture of research center made single crowns and incomplete or full inclusion fixed fractional false teeth, just as seat side periodontal bracing, glue fixed halfway false teeth, post center frameworks, and in orthodontic applications. Resin pre-impregnated FRC has been appeared to have satisfactory flexural modulus and flexural solidarity to work effectively in the oral cavity. The presentation of the FRC framework relies upon the polymer lattice just as fiber type, volume part, and the nature of the fiber-polymer grid interface. Notwithstanding mechanical execution, the arrangement of the polymer lattice and filaments likewise has a significant job in the holding capacity of FRCs to the luting tar concretes and to the veneering composite gum. Fi- 
ber-strengthened composites are by and large progressively utilized as options for traditional materials basically as a result of their high explicit quality, explicit solidness and tailorable properties. Likewise the viscoelastic character of composites renders them appropriate for superior basic applications like aviation, marine, vehicle, and so forth. Be that as it may, these materials are very particular from metals in light of the fact that the previous display a few unconventional methods of disappointment (grid crazing, delamination, fiber disappointment and interfacial bond disappointment because of de-holding) and collaboration at micromechanical, for example constituent level. A few systematic methodologies are accessible as micromechanical, full scale mechanical and auxiliary models/speculations because of examinations completed for both static and dynamic execution of composites. A micromechanical study has been performed to research the mechanical properties of unidirectional fiber fortified composite materials under transverse pliable stacking. Specifically, the impacts of various properties of interphase inside the delegate volume component (RVE) on both the transverse successful properties and harm conduct of the composites have been examined. So as to assess the impacts of interphase properties on the mechanical practices of unidirectional fiber fortified composites thinking about irregular dispersion of strands, the interphase is spoken to by pre-embedded firm component layer among grid and fiber with strain and shear mellowing constitutive laws. Results show a solid reliance of the RVE transverse successful properties on the interphase properties. Moreover, both the harm commencement and its advancement are likewise plainly affected by the interphase properties. Fiber strengthened composites utilized in lightweight structures have been discovered various applications in avionic business for their high explicit quality and solidness. The expanding utilization of these materials in the enterprises requires productive innovations to foresee the mechanical practices of such composites. The present pattern of work to address the business' prerequisite is to supplement it with new micromechanical numerical technique [8]. Two dimensional photo elastic models of fiber-strengthened composite-material setups were intended to research the impacts of different fiber-end shapes, different fiber game plans and broken filaments on the shear-stress circulation in a versatile lattice. Greatest shear worries in the grid in the region of fiber discontinuities are introduced. The pinnacle pressure coming about because of a steadily tightened fiber was seen as marginally higher than that from a square-finished fiber and a round-finished fiber created a pinnacle pressure which was somewhat lower than that from the square-finished fiber. Peak stresses coming about because of two square-finished strands butted intently together were impressively higher and diminished with expanding hole length between fiber ends. It had little effect whether the hole between the butted fiber closes was open, reproducing a void coming about from a wrecked fiber, or loaded up with network material [9]. The dark porcelains used to cover the metal foundation are likewise unesthetic and must be secured with a sufficient thickness of body porcelain. Porce- 
lain is a weak material and can possibly crack and split away from the metal. Furthermore, porcelain is more diligently than finish and can seriously harm unrestored contradicting teeth. From a financial stance, the manual creation of metal systems and their porcelain facade is tedious and requires a significant level of expertise and generous expenses.

Composites are propelled materials establishing of at least two synthetically particular constituents on a large scale, having an unmistakable interface isolating them. At least one broken stages are in this way, installed in a consistent stage to frame a composite. In the majority of the circumstances, the irregular stage is generally harder and more grounded than the ceaseless stage and is known as the fortification though, the constant stage is named as the grid. The framework material can be metallic, polymeric or can even be ceramic. When the grid is a polymer, the composite is called polymer lattice composite (PMC). The fortifying stage can either be sinewy or non-stringy (particulates) in nature. The fiber strengthened polymers (FRP) comprise of filaments of high quality and modulus installed in or clung to a grid with unmistakable interface between them. In this structure, the two strands and framework hold their physical and substance characters. All in all, strands are the chief burden bearing individuals while the lattice places them at the ideal area and direction, goes about as a heap move medium among them and shields them from ecological harms [10]. The utilization of fiber-fortified composite cover materials in aeronautic trade or in applied building has expanded quickly as of late. In various cases including the plan of composite structures there is a requirement for increasingly refined examination that considers marvels, for example, dynamic breaking and inelastic or nonlinear distortion of the composite materials. Such investigation is required not exclusively to anticipate the deformational reaction, yet additionally to give a technique to assess the exact worries to be utilized in disappointment predictions. Most of the propelled composite materials have natural networks; in this manner, there is a huge nonlinear pressure strain conduct present the transverse way of lamina and especially in shear twisting. A critical number of full scale mechanical models have been proposed to speak to the constitutive connection of fiber-strengthened composite materials, for example, nonlinear flexibility models. In expansion, different disappointment rules have additionally been proposed to anticipate the beginning of harm in single layer inside the fiber-fortified composites [11]. The reason for consolidating at least two-component materials to frame a composite material is to get a lot of material properties not attainable by any of the component materials acting alone. In the previous two decades, the accessibility, decent variety, and usage of basic composite materials have expanded at an exceptional rate. This is for the most part because of the ongoing improvement of high modulus filaments and to the earnest need of light weight, high materials for the aviation and related industries. Together with the manifestations of new composite materials and the advancements of new creation procedures, different parts of physical properties of composite materials 
have been explored and various methodologies for the better comprehension of the material practices have been proposed [12]. The utilization of fiber-fortified composite materials for the development and restoration of structural building structures is generally new. Basic individuals are routinely joined by blasted associations. Catapulted associations are moderately simple to gather and keep up and are fit for moving the high loads that normally happen in structural designing structures. Presently there is a genuine absence of information on the conduct and structure of darted associations for fiber-fortified composites [13]. Organic framework usefulness depends on interconnections of neurons. The minor truth that the essential registering component of the human data handling framework is moderately moderate yet the general preparing activity is accomplished in two or three hundred milliseconds proposes that the premise of organic calculation is few sequential advances, each happening on a monstrous equal scale. In this intrinsically equal engineering, every one of the handling components is privately associated and generally basic [14]. Procedure actuated leftover worries in cutting edge composite overlays are known to be brought about by crosslinking of polymer sap, anisotropy of thermo mechanical properties of unidirectional fiber-fortified lamina, and sidelong imperatives of nearby anisotropic laminae. Crosslinking happens during the restoring procedure, and the concoction response including both gum macromolecules and crosslinking operator brings about network shrinkage. By and large, most crosslinking happens at the most noteworthy temperature during fix; subsequently, material consistency may allow unwinding of the greater part of the initiated shrinkage stress [15].

Support preforms and strategies for making the same for use in fiber-fortified composite materials Structures are uncovered, in which the fortification preforms contain first and Second support preform components which incorporate Strength fortification filaments that are in wanted directional direction. AS is known in the earlier craftsmanship, normally Such parts comprise of fortification materials installed in network materials. The support part might be produced using materials. For example, glass, carbon, earthenware, aramid, polyethylene or potentially different materials which display wanted physical, warm, synthetic as well as different properties, boss among which is incredible Strength against Stress disappointment. Using Such support materials which eventually become a constituent component of the finished segment, the ideal attributes of the fortification materials, Such as high Strength, are granted to the finished composite component. In tending to the issue of how to expand the Strength of the crossroads or join between constituent components against the partition of one of the components from the other. A thought is that while the support filaments themselves are generally described by (in addition to other things) their incredible Strength against applied powers, especially in their long or straight measurement, the different network materials utilized in these applications don't have Strength in any measurement practically identical to that of the fortifica- 
tion preform fortification strands. Framework materials typically are chosen essentially for having characteristics Such as the capacity to tie fortifying filaments to one another So as to move powers between the strengthening strands and for concoction or warm obstruction, for which high Strength is given low need. To be sure, as recently brought up, a target in utilizing the support constituent in composite materials in any case is to upgrade the Strength attributes of the composite Structure far in abundance of that achievable utilizing the network material alone. Accordingly, crossroads depending on grid material in essence for their Strength are deficiently Strong for this proposed use. The interest for quick, precise automated controllers is ever expanding. Exact end-effector conveyance and high operational speed are two contending plan prerequisites which numerous current mechanical workstations neglect to fulfill at the same time. One significant purpose behind this horrible showing can be the auxiliary adaptability of the controller. Static diversions and vibrations disintegrate end-effector (EE) precision, while the heap conveying limit (LCC) is restricted by the auxiliary quality of the connections. Because of the normally mind boggling state of the connections of automated arms and the entangled mechanical properties of overlaid composites, limited component examination (FEA) is increasingly reasonable for foreseeing the versatile conduct of composite controllers. Consequently, limited component based execution measures have been actualized in this work [16]. Additive assembling (AM) advances have been effectively applied in different applications. Combined affidavit demonstrating (FDM), one of the most well known AM strategies, is the most generally utilized technique for manufacturing thermoplastic parts those are basically utilized as fast models for useful testing with favorable circumstances of ease, insignificant wastage, and simplicity of material change. Because of the naturally constrained mechanical properties of unadulterated thermoplastic materials, there is a basic need to improve mechanical properties for FDM-created unadulterated thermoplastic parts.

Wandering are the essential structures where filaments are provided a meandering being various strands or packages of fibers twisted into a bundle or creel, the length of the meandering being as much as a few kilometers, contingent upon the bundle size. Meandering or tows can be woven into textures, and a scope of texture developments are accessible economically, for example, plain weave, twills and different glossy silk weave styles, woven with a decision of wandering or tow size contingent upon the weight or areal thickness of texture required. Textures can be woven with various types of fiber, for instance, carbon in the weft and glass in the twist course and this expands the scope of properties accessible to the designer. One bit of leeway of textures for fortifying reasons for existing is their capacity to wrap or fit in with bended surfaces without wrinkling [17]. The most significant factor we need composite materials is the flexibility of their properties that enables them to be used in several fields. Their light weight, corrosion resistance and durability are other reasons. 


\section{FRC/AMM}

For the advanced fiber reinforced composite (FRC) materials with the combination of advanced manufacturing method (AMM) the additive method for carbon is one of them.

\subsection{Additive Manufacturing of Carbon Fiber}

Added substance fabricating (AM) is characterized as a procedure of joining materials to make objects from 3D model information, normally layer upon layer, instead of subtractive assembling methodologies. AM advancements make it conceivable to construct an enormous scope of models or utilitarian segments with complex geometries that can't or if nothing else hard to be produced by regular strategies. Contrasted and regular strategies, AM can abbreviate the plan fabricating cycle and in this manner decrease the creation cost and increment the seriousness. Likewise, because of the enhancements of procedures and headways of displaying and plan, AM advances have been engaged with more extensive different applications in the previous three decades. The biggest three quick expanding utilizations of AM fall into the zones of aviation, car, and clinical. Different applications incorporate engineering, instruction, style and so on. The principal created AM strategies are normally applied to manufacture unadulterated plastic parts those are for the most part utilized as fast models for utilitarian testing. AM procedures incorporate stereolithography contraption (SLA) from photopolymer fluid, intertwined affidavit demonstrating (FDM) from plastic fibers, overlaid object producing (LOM) from plastic covers and particular laser sintering (SLS) from plastic powders. Anyway FDM is the most generally utilized strategy among all the AM procedures for manufacturing unadulterated plastic parts with ease, negligible wastage and simplicity of material change. Before FDM-creating, level layers and the thickness of each layer can be set contingent upon the requests of clients. In FDM forms, the fiber on the spool is taken care of into the liquefier head with the guide of taking care of weight created from a driver gear and a furrowed bearing. Plastic parts can be assembled layer by layer through storing the fiber material which is warmed to glass change state and expelled through the expulsion spout at a consistent temperature. The apparatus way produced by the product and stores the primary wanted layer at a time onto the print bed to frame an establishment for the part. At the point when the layer is finished, the assemble stage moves descending for one layer thickness for following layer of fiber material fabrication. Each single layer will be stored over and over on the past one similarly until the part is finished. In the FDM machine with double expulsion spouts, construct fiber material with another shading or bolster fiber material can be all the while expelled during that time spout if essential. After FDM creation, the help material can be effectively evacuated either precisely or artificially (e.g., utilizing dissolvable). For the testing examples with carbon fiber substance of $5 \mathrm{wt} \%$ and normal length of 150 $\mathrm{mm}$ for model, the bend was chosen from the consequences of five examples, 
contingent upon the greatest number of qualities those were the most shut to the mean estimation of each malleable properties (Figure 1 represents the Additive manufacturing of carbon fiber reinforced thermo-plastic composites using fused deposition modeling).

The degree of the interior harm was resolved utilizing estimated changes in the dynamic properties of the framework (misfortune factor, dynamic solidness and mode shape), to get the reaction data at higher frequencies a modular investigation framework was worked around the presentation qualities of a laser doppler vibrometer (LDV) and an electronic spot design interferometer (ESPI). These two gadgets gave integral data to the assurance of the dynamic attributes of every vibration mode. With this framework, harm actuated changes in the dynamic qualities of composite materials were estimated at frequencies up to 10 $\mathrm{kHz}$. The aftereffects of this investigation demonstrated the accompanying. Torsion modes give the most affectability to confined interior damage. The assessment of higher recurrence NDI information requires the capacity to connect the deliberate misfortune factor and resounding frequencies with the genuine mode shape. The information acquired over the recurrence scope of the test could be diminished to a progression of slants that give a touchy sign of the material condition. The affectability of the dynamic technique to restricted harm is constrained by the estimation of the misfortune factor [18]. Two interferometric techniques were used to obtain the dynamic information from each target.

Laser Doppler Vibrometry (LDV) was used to measure the frequency response of the target, while an electronic speckle pattern interferometer (ESPI) recorded the associated mode shapes. Each of these interferometric techniques provides sensitivity for dynamic measurements that is better than more traditional measurement approaches.

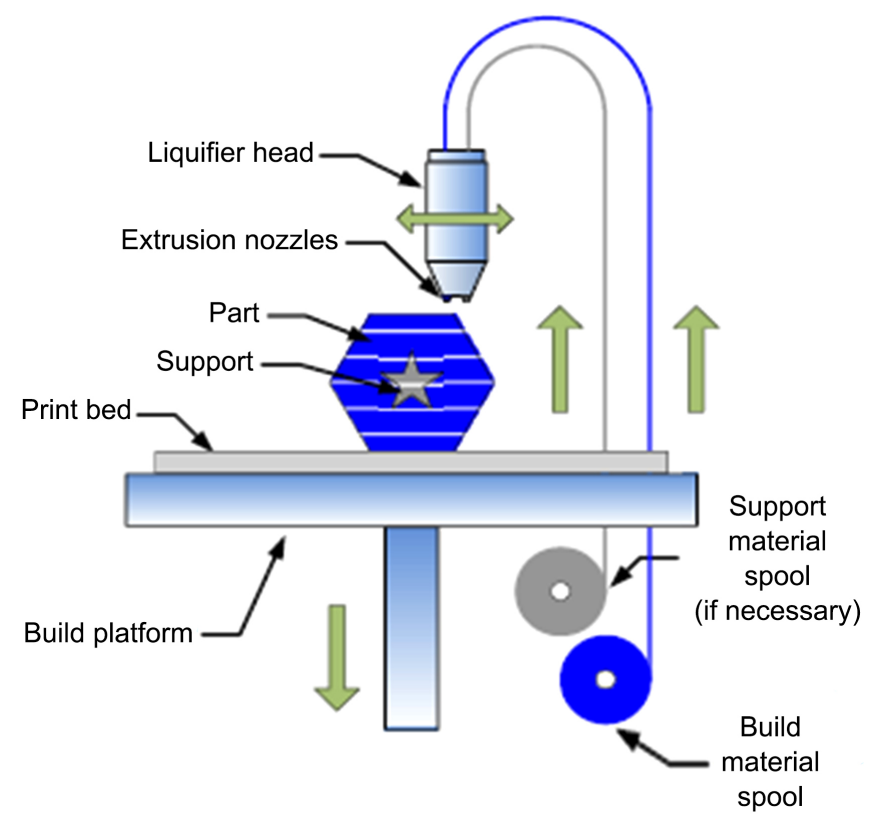

Figure 1. Represents the additive manufacturing of CFRTPM. 
LDV relates the instantaneous velocity at a point on a target to the Doppler frequency shift in light scattered from that point according to the relationship given by

where

$$
\text { Źf } \approx \frac{2-V}{X}
$$

Źf = Doppler shifted frequency of the scattered laser light;

$\mathrm{V}=$ Target velocity;

$\mathrm{X}=$ wave length of laser beam.

which also represents through Figure 2.

Impacts of carbon fiber content on malleable properties (counting rigidity, Young's modulus, sturdiness, yield quality and pliability) of CFRP composite examples. Boxplots were utilized to communicate the dispersions of information at every carbon fiber content. The case goes secured from $25 \%$ to $75 \%$ percentile of certainty span. Mean an incentive in the crate was utilized to communicate the patterns on impacts of carbon fiber content on tractable properties. In the accompanying Sections, the strainestress bends were chosen in the same. To augment the harm actuated changes in the misfortune factor two conditions must be met. To begin with, the harm ought to be focused in a zone of high arch (for example high-strain vitality). This condition follows from the meaning of the misfortune factor estimation. Second the separation between sufficiency tops in the standing wave ought to be littler than the physical degree of the harm to be recognized. At the point when the top-to-top separation is bigger then the harm zone, the commitment of the imperfection to the damping related with that vibration cell is decreased. The affectability conditions suggest that there is an ideal mode shape for delivering the greatest sign of a specific harm zone. Likewise the ideal reverberation recurrence will be the least that meets the two affectability rules. The affectability conditions demonstrate that the adjustments in the dynamic qualities of torsional modes are bigger than for higher frequencies. The outcome is then a negative torsional slant for the harmed bar.

The utilization of fiber-fortified composites is the way to lightweight development, which is essential for present day life. Aviation, car, shipbuilding or railroad, rotor edges for wind vitality generators or sports supplies-the applications

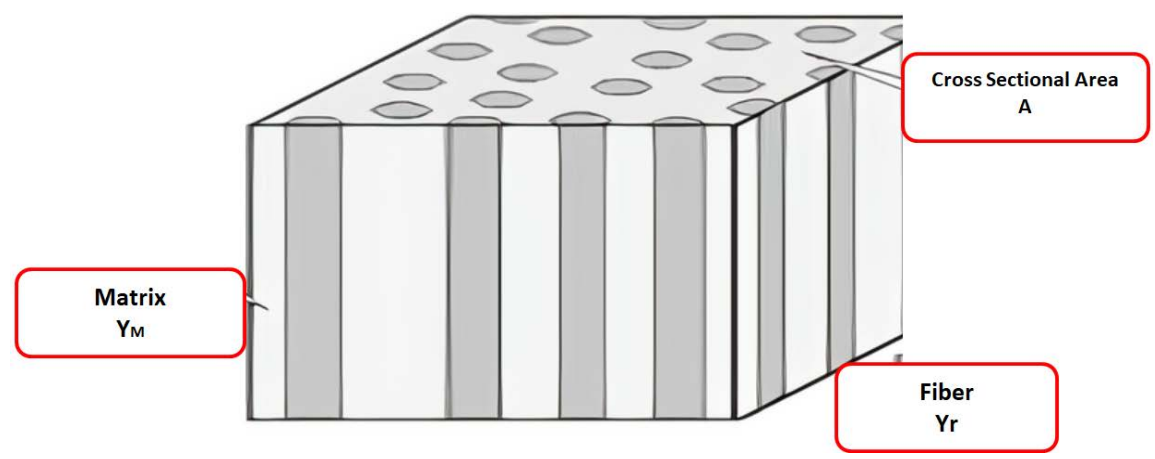

Figure 2. Wavelength through velocity matrix. 
for fiber-strengthened composites are complex. Glass or carbon filaments, woven, unidirectional or multiaxial are the most widely recognized fortifications. Thermoplastic or thermosetting materials are utilized as grids. In some elite applications, epoxy pitches are utilized as lattice materials. All known assembling innovations for fiber-strengthened composites are utilized in the business in blend with epoxy gums. Ski posts are made by utilizing fiber twisting of carbon strands in blend with anhydride restored epoxy resins. Machine parts are produced by utilizing amine relieved glass fiber prepregs. Profiles are delivered by pultrusion utilizing fluid tar frameworks. Aviation parts are made by utilizing carbon fiber pre-pregs dependent on tetra practical epoxy pitches restored with sweet-smelling amines in an autoclave. The most well known assembling advancements are infusion innovations like tar move shaping (RTM), single-line infusion (SLI), vacuum helped tar move forming (VARTM) and so forth because of the moderately short assembling cycles. Rotor sharp edges for wind vitality generators are produced predominantly by utilizing vacuum-helped imbuement procedures. In any case, the viscosities of the sap frameworks utilized for infusion advances should be low. In designing composite parts for example a driving rod for a games vehicle, the strengthening fiber or texture are nonwoven and their direction towards the power along the part is of most extreme significance. Be that as it may, the decision of pitch and hardener is significant too to coordinate execution just as creation cycle needs. Obviously, any improvement of the sap execution is free to assist with improving the exhibition of the composite parts. In the years 2002/2003, the principal business evaluations of surface-changed silica nanoparticles were brought into the market. They are fabricated in situ legitimately in the epoxy gum by an altered sol-gel process. The circular particles have a normal breadth size of $20 \mathrm{~nm}$ and an extremely thin molecule size appropriation. In an ongoing, broad survey, the property enhancements of epoxy tars adjusted with silica nanoparticles have been investigated. Incorporated into relieved mass epoxy saps, paying little heed to the hardener decision, they do improve a few properties like quality and modulus (true to form for mineral particles). Besides, they improve strength which is more subtle, yet a known impact when utilizing glass microspheres in epoxy details. Cyclic weariness execution can be improved fundamentally by a few hundred percent [19].

There were comparative connections between carbon fiber content versus sturdiness and carbon fiber content versus yield quality as showed. It tends to be seen that both mean estimations of durability and yield quality had a general diminishing inclination when carbon fiber content expanded from $0 \mathrm{wt} \%$ to 10 $\mathrm{wt} \%$ (aside from a delicate ascent at $5 \mathrm{wt} \%$ carbon fiber content). Sturdiness and yield quality of the parts with carbon fiber content lower than $10 \mathrm{wt} \%$ were bigger than those of the parts with carbon fiber content higher than $10 \mathrm{wt} \%$. At the point when carbon fiber content surpassed $10 \mathrm{wt} \%$, these two mechanical properties expanded once more. The biggest mean qualities for both sturdiness and 
yield quality could be found in unadulterated plastic example.

The instruments for the property upgrades of mass epoxy gums have been very much explored and are completely understood. 2 Two fundamental toughening components have been distinguished for silica nanoparticles: confined shear groups started by the pressure fixations around the fringe of the nanoparticles and the de-holding of the silica nanoparticles followed by ensuing plastic void growth. In a fiber-strengthened framework, furthermore systems like fiber crossing over and fiber de-holding may assume a specific job; fiber pullout presumably a minor one. Mircroscopical investigations of break surfaces uncovered a few contrasts between the covers with nanosilica and without nanosilica at regular expansion levels around $10 \mathrm{wt} \%$. The crack disappointment mode changes from interface disappointment between glass or carbon fiber and epoxy grid to a blend of interface disappointment and lattice disappointment for the overlays with nanosilica.

\subsection{Cell Walls Plantation Surface with FRC}

Utilizing extensiometry and polarization confocal microscopy, we give here the principal affirming proof that the mean direction of cellulose fibrils in the composite divider decides its mechanical properties. When there is a favored direction of the cellulose fibrils, the cell divider is fortified corresponding with the fibrils. Composite materials comprise of firm solid fibers, plates or particles set in a moderately agreeable matrix. The mechanical properties of fiber-put together composites depend with respect to numerous factors, for example, fiber types, directions, and general design. Plant cell dividers can be considered as composite materials. They comprise of hardened semi crystalline cellulose fibrils, cross-connected by hemicellulose polymers, inserted in a gel-like framework of pectins. Cellulose fibrils have a background marked by being considered as the heap bearing components in plant cell walls. The epidermis, the covering cell layer of plants, has run of the mill examples of mean cellulose direction and its mechanical properties are of most extreme significance for the control of size and state of the plant body. The direction of the cellulose fibrils was uncovered by congo red recoloring and polarization confocal microscopy. In the event that cellulose fibrils are themselves adjusted in equal, the fluorescence force of the divider is at a most extreme when the vector of the enraptured energizing laser pillar is corresponding to the overwhelming cellulose direction [20]. It is at the very least with the vector opposite to the fibrils. Dividers with an absolutely irregular direction of the cellulose fibrils have no transcendent excitation direction and their fluorescence power doesn't rely upon the direction of the vector of the energizing bar. In onion, the divider has an anisotropic design. Cellulose fibrils have a mean direction corresponding with the longitudinal pivot of the cell, as is delineated by the high power of Congo Red fluorescence when the polarization vector of the laser light is corresponding to this hub (Figure 3 indicates Polarization confocal micrographs of onion) [20]. 
It has an arbitrary direction of the cellulose fibrils. There is no distinction in fluorescence power contingent upon the direction of the laser shaft. In the two figures, the bolts show the direction of the electrical vector of the laser bar and the embedded wedge delineates the shading coding of the fluorescence power. Low, middle of the road and high fluorescence power are listed as blue, green and red separately portions of the two model tissues were exposed to uniaxial strain explores in two ways, in the plane of the external (peri clinical) divider. For the anisotropic onion epidermis these bearings were equal and opposite to the mean cellulose direction. The upper brace was joined to a vibration exciter (Figure 4 represents the unidirectional tensile strength).
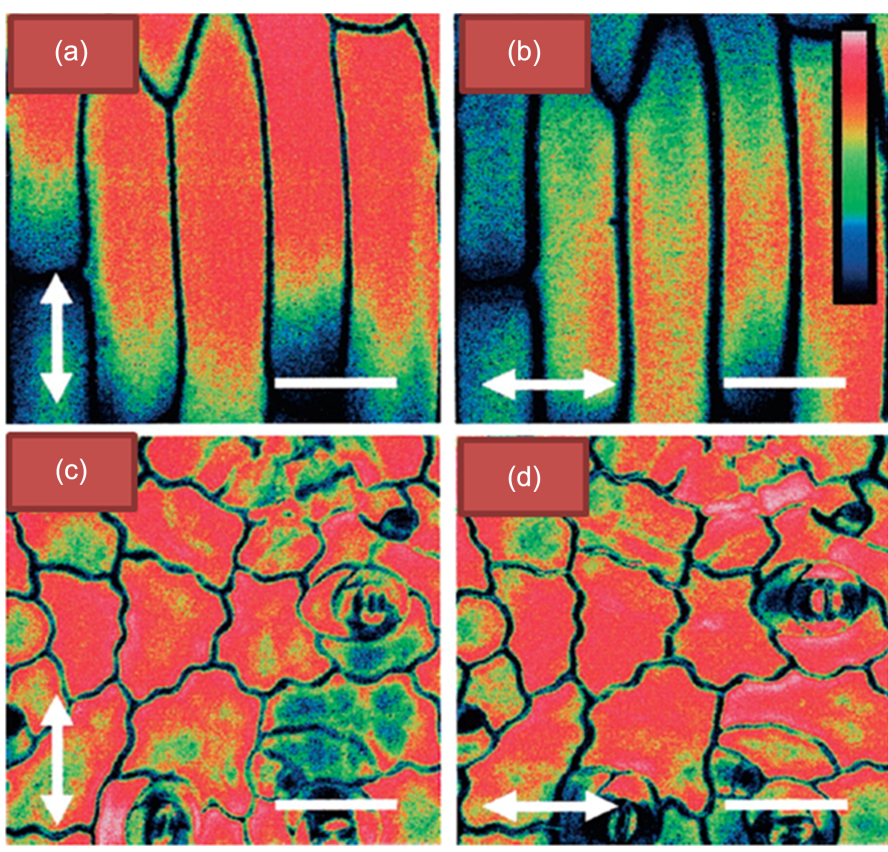

Figure 3. Indicates polarization.

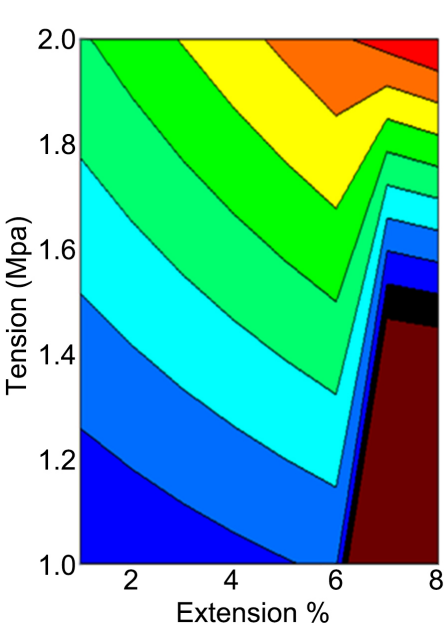

(a)

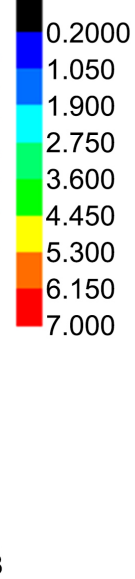

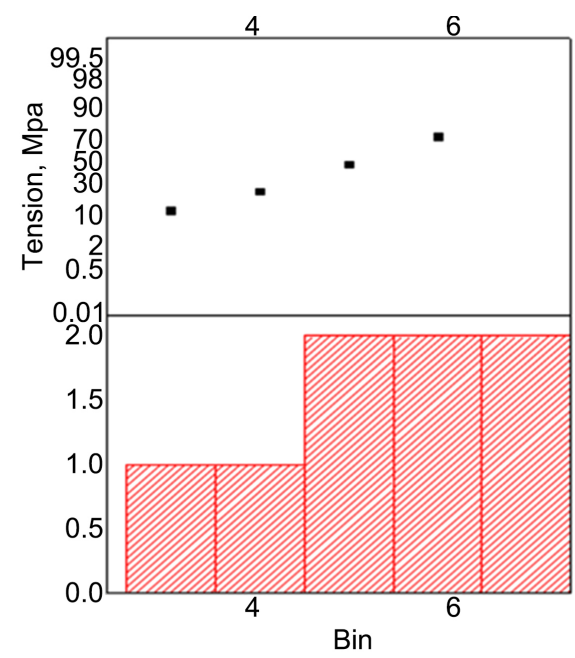

(b)

Figure 4. Represents the unidirectional tensile strength (a) and (b). 


\subsection{Novel FRCM for Sustainable Geopolymer Matrix}

Geopolymers are speaking to the most encouraging green and eco-accommodating option in contrast to standard Portland concrete and cementitious materials, on account of their demonstrated strength, mechanical and warm properties. Be that as it may, notwithstanding these highlights, the poor tractable and bowing qualities for the most part displayed by geopolymers because of their fragile and earthenware like nature, can without much of a stretch lead to calamitous disappointment and speak to the fundamental disadvantage constraining the utilization of those materials in a few applications. Fiber fortified geopolymer composites might be viewed as an answer to improve flexural quality and crack strength. Various kinds of scattered short filaments are here examined as a fortifying part for a geopolymer network dependent on a soluble base actuated spoon slag. It has been exhibited that both natural and inorganic filaments can prompt a noteworthy flexural quality improvement. In addition, the researched geopolymers show an expansion in durability, therefore deciding a change from a weak disappointment mode to an increasingly pliable one. Flexural strength and post-breaking malleability of fiber-fortified examples were likewise explored. Burden diversion bends for geopolymer composites, alongside unreinforced control tests (GS) were resolved post-breaking conduct is essentially improved by fiber addition. Reinforcing filaments are plainly adding to broaden the region under the non-straight part of the heap avoidance bend and, in this way, to upgrade the vitality consumed by the material during crack. All additional filaments can decide for the strengthened geopolymers a change from a plain straight conduct (GS), where the vitality assimilation limit just concerns the concurrent beginning of break and inception of splitting, to a run of the mill pliable conduct, where the vitality ingestion is fundamentally dictated by miniaturized scale splits development and engendering and dynamic fiber debonding up to disappointment. Additionally, the vitality ingestion limit is essentially impacted by the sort of strengthening strands utilized in the blends: carbon and PVC filaments show higher break durability and pliability, as it tends to be seen from the more extensive bend branch that portray the composites' conduct in the wake of arriving at the main split burden. These filaments were exhibited to have a superior spanning conduct inside the split network as they had the option to incite a good draw out instrument that happened when crack emerged. Geopolymers have been as of late viewed as promising substitutes for OPC in various applications fields, including that of designed fiber fortified composite materials dependent on cementitious or inorganic frameworks. In the previous years, in realities, fiber strengthened composite materials have been assuming a significant job in recovery and fix of harmed brick work and solid structures, because of their performing properties such high solidarity to weight proportion, erosion obstruction and simplicity of application. Woven textures, mats or unidirectional strands, for example, carbon, E-glass, Kevlar or basalt filaments have been so far the most generally used to cast ceaseless fiber-strengthened compo- 
sites in structural building applications. All the more as of late, auxiliary composite materials acquired from inorganic framework have been intended to manage the significant downsides getting from the utilization of natural polymer saps. Actually, a fundamentally low protection from UV radiation and high-temperatures is to a great extent constraining natural network use in a wide field of uses. With the intend to go on with the exploration on inorganic lattices, fiber strengthened composite materials dependent on geopolymers are now being researched. Various kinds of fiber fortifications have just been utilized in different geopolymer frameworks to improve their flexural quality, sway conduct and disappointment mode. It has been accounted for that adding strengthening filaments to a weak lattice assists with controlling smaller scale and large scale breaks dispersion through the material by creating a connecting impact just as to change the post-splitting conduct of the material from a fragile crack mode to a pliable one, because of its upgraded strain vitality dissemination capacity [21].

\section{FRCM/RCP}

Fiber reinforced composite materials (FRCM), the most curiosity of this work is reusing process (RCP) and its reusing methods. In up and coming age, the most important innovation will reuse process in the viewpoint of condition and common health. Methodology to recover carbon fiber from the basic carbon composites utilized in original composite airplane has been known for 10 years. With the coming of the Boeing 787, new, further developed composites have entered the creation arrange and require another way to deal with recovery. These cutting edge composites no longer comprise of solid fiber-fortified materials, however are very much planned multi-layers of composite and different materials, mostly for toughening purposes. Carbon fiber strengthened composites have upset the aircraft business. Following 50 years of all aluminum airplane, the up and coming age of planes will be built of composite material for most of their auxiliary components. The superior airplane in such manner, with $50 \%$ of it's general weight being carbon-fortified composite, is the Boeing 787 Dreamliner, scheduled for business creation by 2009. During a time of absolute lifecycle getting ready for each major mechanical venture, Adherent Technologies, Inc. (ATI) has been associated with examining the recovery of these airplanes for quite a long while. While early work was performed on standard composite materials, the accessibility of real creation tests of the materials utilized in the new airplane has added another measurement to the reusing issue.

\subsection{Recycling of Fiberglass}

The breeze vitality industry is one of the quickest developing application areas of composites, where fortification filaments are utilized in the assembling of light rotor sharp edges. Thinking about the constrained lifetime of turbine sharp edges, a developing number of wind turbines will begin to be decommissioned. Turbine cutting edges are by and large landfilled at their finish of-life, which ex- 
ceptionally impacts nature. This proposes a methodical plan joining mechanical reusing and $3 \mathrm{D}$ printing to reuse the important constituents of the piece cutting edges and reuse them in a combined. Fiber Fabrication (FFF) process with the point of improving the mechanical presentation of 3D printed parts. Mechanical crushing coordinated with a twofold sieving component is used to recoup the fortification filaments. Tractable test examples with $5 \mathrm{wt} \%$ fiber content are manufactured from the reused strands and plastic pellets and their mechanical properties just as interior microstructure are examined. The outcomes exhibit an improvement of $16 \%$ and $10 \%$ in the flexible modulus and extreme quality of the strengthened composite fiber when contrasted with the economically accessible unadulterated PLA fiber [22] (Figure 5) indicates the proposed three-stage grinding methodology for the mechanical recycling of wind turbine blades.

The prevalent mechanical properties of composite materials give a leaving chance to fabricate structures that are lightweight and of high quality, attributes that have prompted many building applications for composites. The breeze vitality industry speaks to one of the quickest developing application parts of composites, where support filaments, for example, fiberglass or carbon strands, a plastic polymer, for example, polyester or epoxy, and a center material are utilized to assemble solid and consistent rotor cutting edges. The sensational development of wind industry in the course of recent years has brought about a broad measure of end-of-life rotor edges. Momentum courses to discard turbine cutting edges at their finish of-life include landfill and burning, strategies that are related with ecological effect. Given the non-biodegradable nature of turbine sharp edges, ongoing ecological enactment has progressively requested for the reusing and supplanting of turbine edges sooner rather than later. Recent examination endeavors in the zone of wind vitality have been centered around the improvement of practical techniques for the reusing and reuse of rotor edges. To address this essential test, researchers have turned to compound and pyrolysis methods to recuperate glass filaments from end-of-life turbine cutting edges. Despite the high mechanical properties of the reused strands, these procedures show little guarantee as far as commercialisation because of the utilization of risky synthetic substances and additionally unreasonable expense. Mechanical pounding is the main reusing method, which has discovered its approach to

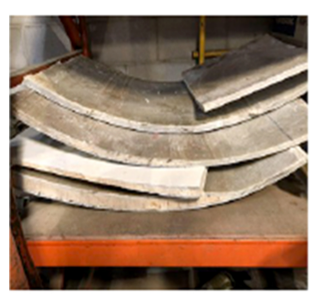

Wind turbing blades

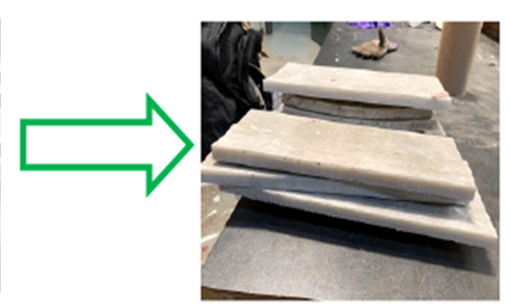

Cutting blages

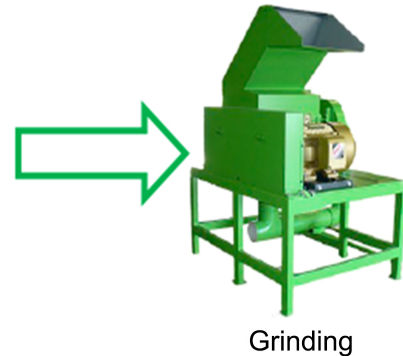

Stage-2

Grinding

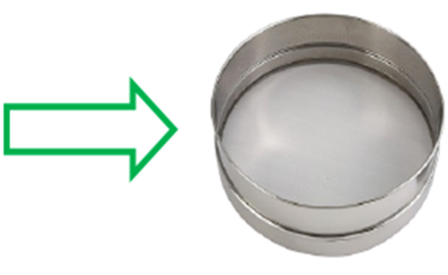

Sieving

Stage-1

Stage-3

Figure 5. Indicates the proposed three-stage grinding methodology. 
modern application [9]. Contrasted with warm and compound procedures, this strategy offers a clear and monetarily possible plan for the reusing of composites, especially glass fiber strengthened materials. An ongoing examination study explored the attainability of reusing the precisely recuperated filaments from wind turbines sharp edges to fortify polypropylene. The outcomes have uncovered that the mechanical properties of the reused composite parts made of the destroyed strands are similar to those watched for parts made of pyrolyzed filaments. They have additionally demonstrated that rather than pyrolyzed strands, the destroyed glass filaments hold the glass measuring. Thus, mechanical pounding can be considered as a basic and direct answer for handle the glass fiber strengthened plastics (Figure $6 \&$ Figure 7 show stress/strain curve and test up materials with PLA).

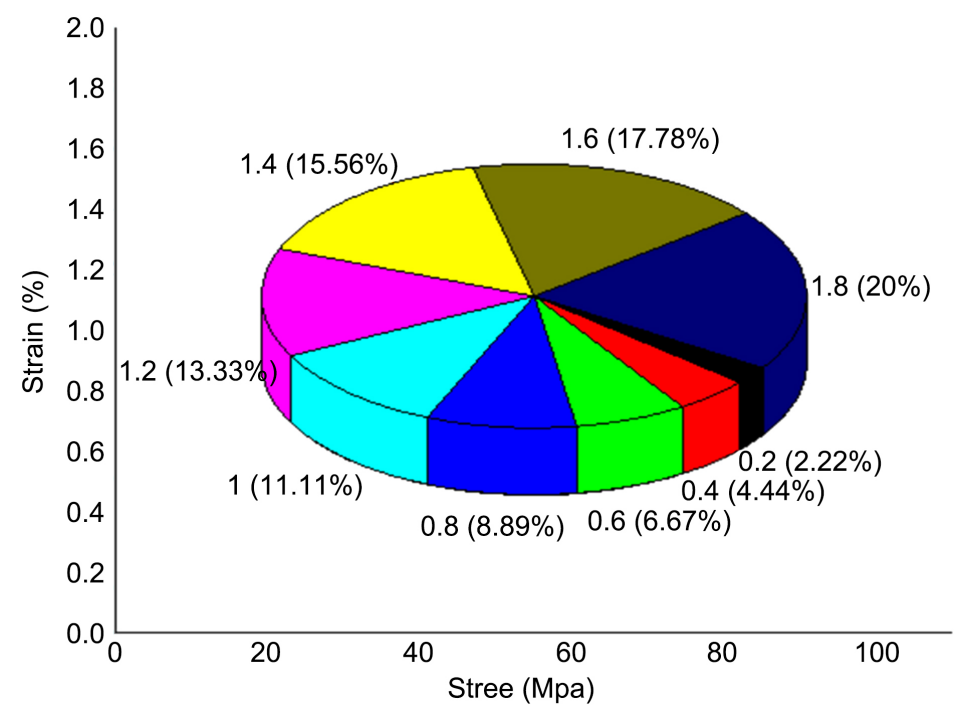

Figure 6. Shows stress/strain curve and test up materials with PLA.

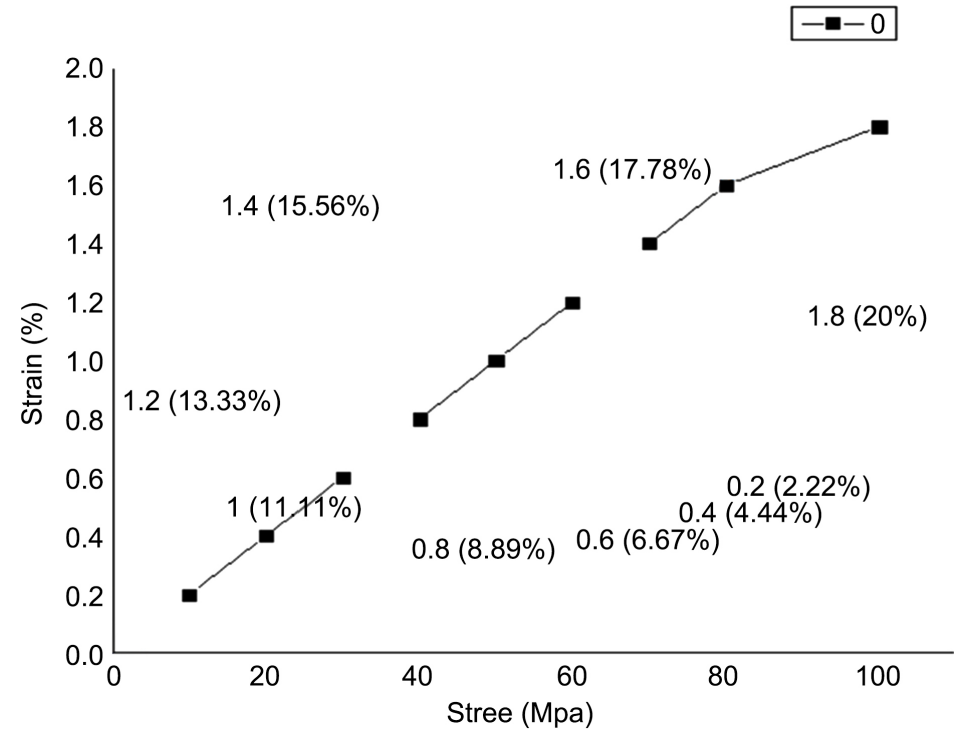

Figure 7. Shows stress/strain curve and test up materials with PLA (vertical view). 
The microstructures of the unadulterated PLA fiber and RGFRF along the transverse and longitudinal bearings. As it very well may be seen, the PLA fiber shows smooth and round edges with no obvious air bubbles, demonstrating the effective expulsion of the dampness content during the drying out procedure. The RGFRF, then again, contains generally little inside voids that are appropriated all through the fiber. The twofold expulsion process improves the probability of dampness retention by the PLA and ensuing air bubble arrangement likelihood during the expulsion procedure. As saw in the transverse cross segment of RGFRF, glass strands are obvious in the fortified fiber and are all around disseminated all through the cross area. The longitudinal cross segment uncovers that the strands are commonly very much adjusted in the ways of expulsion. This perception proposes that the RGFRF can be treated as a short glass fiber reinforced composite (Figure 8: The tensile properties of the pure PLA and composite tensile test specimen).

In less created and in overpopulated nations, the need to lessen the utilization of non-inexhaustible regular assets and vitality has supported the improvement of minimal effort, sheltered and practical valuable arrangements, such is the situation of moderate houses. This system requires the utilization of neighborhood crude and sustainable materials, and reused constituents as per a procedure that assembles adequately their properties. This is being sought after by a few specialists in different nations like Malaysia, India and China. By utilizing the construction innovation, these materials can be applied to the improvement of lightweight and sturdy valuable parts as per reasonable measures of value control for the structure of particular houses. One way precast solid pieces are utilized in United States since the 1950s, being created by longitudinal pre-assembled concrete thin pillars fortified with latent or prestressed steel wires, lightweight hinders (that can be made by various kinds of materials) bolstered in these shafts,

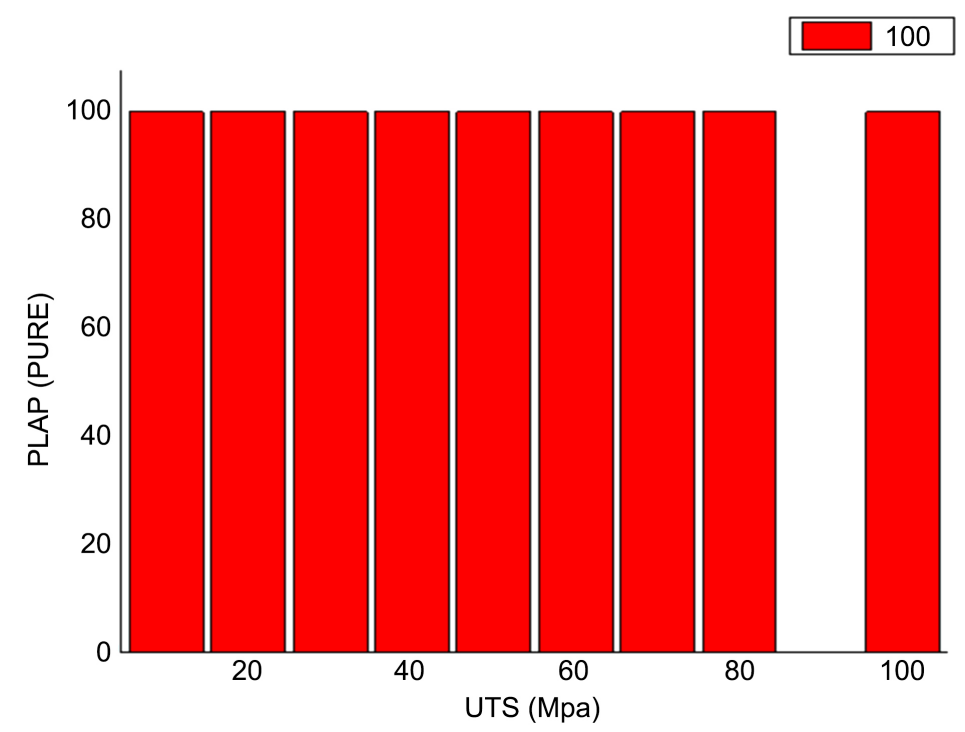

Figure 8. The tensile properties of the pure PLA and composite tensile test specimen. 
and solid spread layer cast in place. This chunk is the most well known deck framework for private structures in a few nations. The straightforward and quick technique for executing, lightness and generally minimal effort makes them profoundly serious, since the utilization of formworks is maintained a strategic distance from, and the necessities for talented labor and time development are diminished. Due to the lightweight character of this kind of pieces, right now assigned by "bar and-square floor framework-B \& B-FS", the lasting burdens moved to their backings (pillars and segments) and establishments are littler than when gigantic RC chunks (heavier) are utilized, with ensuing advantages regarding the expenses of these other helpful components and better conduct of the structure under seismic occasions [23].

\subsection{The Economic and Mechanical Potential of RCP}

Novel reuse esteem model got from the held mechanical presentation of recovered strands in fiber-fortified composites. The proposed recyclate esteem model was utilized to play out a monetary investigation for building up the future shut circle material use of fiber-strengthened composite materials. Best in class reusing of carbon and glass-fortified thermosets was received and brought about a proposed reusing progressive system so as to accomplish an increasingly reasonable condition and crude material cost decrease. The recyclate esteem model demonstrated that around half material cost decreases can be accomplished at tantamount mechanical execution by utilizing reused fiber rather than virgin fiber in suitable applications. From the part of lightweight structure, this cost decrease furnishes the fashioner with new material decisions, suitable for lower cost and assorted solidness plans. The proposed shut circle chain of command reports the significance of further improvement of stringy material reusing, including arranging as indicated by mechanical execution, so as to distinguish application zones beforehand not used and to amplify material manageability and incentive all through the material's lifetime.

Fiber-fortified composite materials, for example, carbon-strengthened epoxy, are utilized widely for requesting high-solidness applications in aeronautical and aviation adaptions where their low auxiliary weight likely prompts expanded eco-friendliness and subsequently to decreased use stage expenses, and condition benefits. All the more as of late, the possibility to diminish these use stage costs and the general ecological effect has pulled in additionally the car business. For instance, BMW utilizes gum transfermoulded (RTM) carbon-fiber fortified plastic (CFRP) segments in their i3-and i8-arrangement. To be sure, it has been demonstrated that a $10 \%$ decrease of the auxiliary load of a vehicle can prompt improved efficiency and a fuel utilization lessening of $6 \%-8 \%$ [24]. This examination study proposed a recyclate esteem model on fiber strengthened composites that have been actualized towards assessing material worth supportability and the effect of a future round, shut circle, material stream. Various vital impediments and suspicions have been applied that directs the materialness and legi- 
timacy of the proposed recyclate esteem model. Given the expectation to survey a future cyclic material reusing stream, proposed recyclate esteem model was actualized utilizing fiber framework information drawn from industry and distributed writing. The exploration was done at an overall level to give a more extensive premise to advance conversation with suggestions for lightweight structure and possible future composite applications. The strengthening fiber materials investigated ran from basic to semi-auxiliary applications also were conventional PAN-and pitch-based carbon just as lignin-based carbon and glass. The connective framework of the fiber-fortified composite was epoxy [25] (Figure 9 shows fibre reinforcement $\mathrm{kg}$ cost with increasing reinforcement performance).

Current common airplane applications have focused on supplanting the optional structure with stringy composites where the support media has either been carbon, glass, Kevlar or half and halves of these. The grid material, a thermosetting epoxy framework is either a $125^{\circ} \mathrm{C}$ or $180^{\circ} \mathrm{C}$ restoring framework with the last turning out to be prevailing a direct result of its more prominent resilience to natural degradation (Figure 10 shows Recycling process from FRCM).

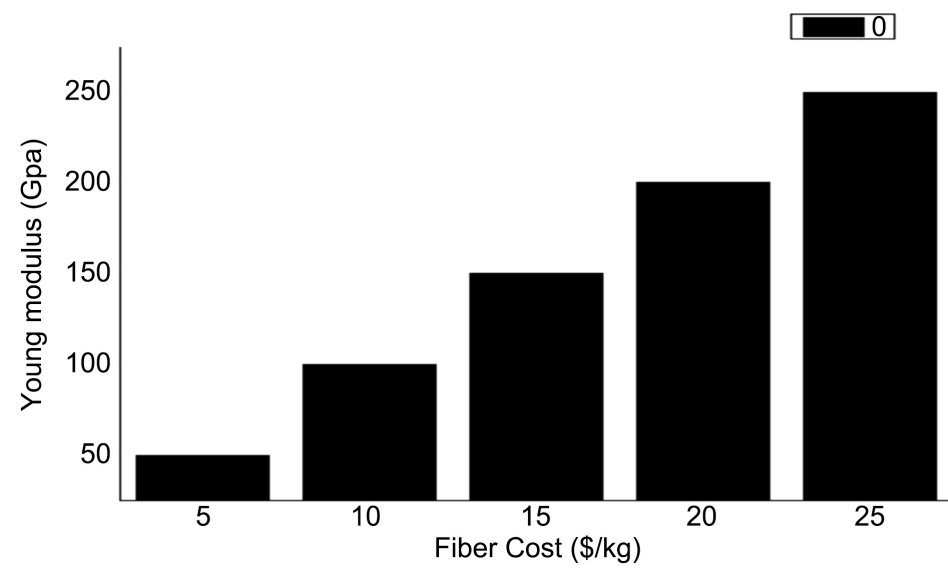

Figure 9. Shows fibre reinforcement $\mathrm{kg}$ cost with increasing reinforcement performance.

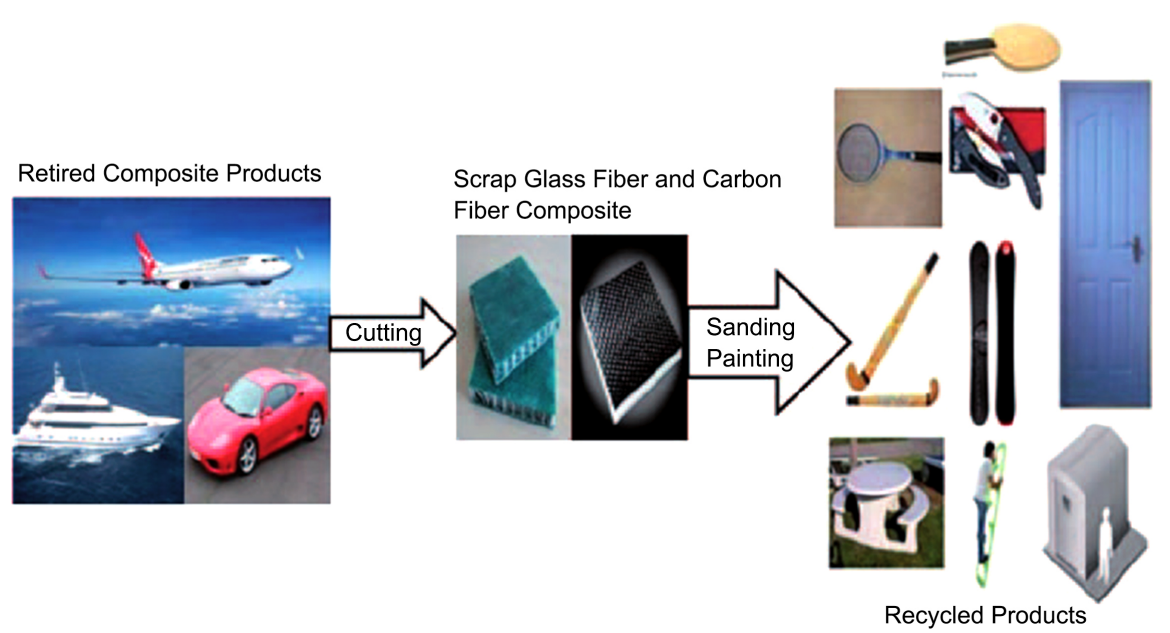

Figure 10. Shows recycling process from FRCM. 


\section{Peridynamic Analysis of FRCM}

Harm commencement and its resulting proliferation in fiber-fortified composites are not comprehended as plainly as they seem to be, for instance, for metals in light of the nearness of firm filaments inserted into the delicate framework material, causing inhomogeneity. Under the supposition of homogeneity, a lamina has orthotropic flexible properties. Despite the fact that this supposition that is appropriate for pressure examination, it becomes flawed while foreseeing disappointment. Most composite structures incorporate scores and patterns, decreasing the quality of the composites as well as filling in as potential disappointment locales for harm commencement. They likewise advance basic disappointment methods of delamination, framework splitting, and fiber breakage. These disappointment modes are intrinsic to the inhomogeneous idea of the composite, accordingly the homogeneous material presumption pollutes disappointment dissect [26]. In spite of the improvement of numerous significant ideas for foreseeing material conduct and disappointment, the expectation of disappointment modes and lingering qualities of composite materials is a test inside the system of FEM. The utilization of FEM to anticipate disappointment can be very testing in light of the fact that remeshing might be required to cause a precise expectation and harm to can just engender in specific ways. Remeshing can be stayed away from by utilizing extraordinary components, for example, durable components. Notwithstanding, these components require from the earlier information on the harm way, which probably won't be accessible. Except if these components are effectively positioned during model age, the harm expectations might be mistaken. Notwithstanding the need to remesh, existing strategies for break demonstrating likewise experience the ill effects of the prerequisite of an outside split development standard. This measure recommends how harm advances from the earlier dependent on nearby conditions, and aides the examination with regards to when and how harm starts and spreads. Thinking about the trouble in getting and summing up exploratory break information, giving such a basis to harm development, particularly in composite structures, plainly presents a significant impediment to crack displaying utilizing customary techniques. This keeps such techniques from being relevant to issues in which numerous harm development happens and cooperates in complex examples. The disfigurement reaction of strong structures exposed to outer powers can be acquired by expecting the structure as a nonstop body or a continuum, without focusing on its atomistic structure. Hence, it is conceivable to perform both static and dynamic examinations of huge structures inside a sensible measure of time. The traditional methodology that is utilized to investigate strong structures is known as "old style continuum mechanics" and has been effectively applied to various issues previously. Inside the traditional continuum mechanics system, it is accepted that the persistent body is made out of a vast number of minute volumes, which are called material focuses. This material focuses connect with one another in particular in the event that they are inside the closest neighborhood 
of one another; at the end of the day, through an immediate collaboration (contact) (Figure 11 represents different bonds existing on FRCM).

A gathering of materials whose modulus of versatility can be custom fitted to explicit necessities is fiber-strengthened composites (FRCs). The modulus of flexibility and other mechanical properties rely upon the sort, structure and amount of fortifying fibers. 10 The holding capacity of FRC material relies for the most part upon the kind of polymer network between the strands. The thermosetting polymer framework, similar to those got with light-polymerized dimethacrylate saps, brings about a profoundly cross-connected polymer lattice that can be adhesively attached to the composite luting concrete with free extreme polymerization, for example, polymer without cross-connected polymer chains, can be broken up somewhat by monomers of composite gum luting concretes and structure an interpenetrating polymer arrange (IPN) holding during polymerization [27]. Slight covered composites have become a significant gathering of materials for present day innovation. Composite material frameworks permit built heterogeneity to be planned into the material to accomplish explicit designing capacities [28]. The significant issue of finding a connection between a plainly visible harm variable and the procedure of harm gathering inside a material is tended to in this article. Monotonic and cyclic distortion conduct has been concentrated in a haphazardly conveyed glass fortified polyester lattice composite [29].

The uses of fiber composite materials are broad because of a few focal points controlled by them, for example high explicit quality and solidness. In any case, their exhibition under effect stacking is commonly poor and it limits their applications. A definite writing review of the mechanics of effect and the presentation of composite materials [30]. Polymeric materials are finding expanded application under conditions in which they might be exposed to strong molecule disintegration. For instance erosive disappointment has been accounted for in polyethylene gas funneling frameworks because of contaminant particulate issue [31].

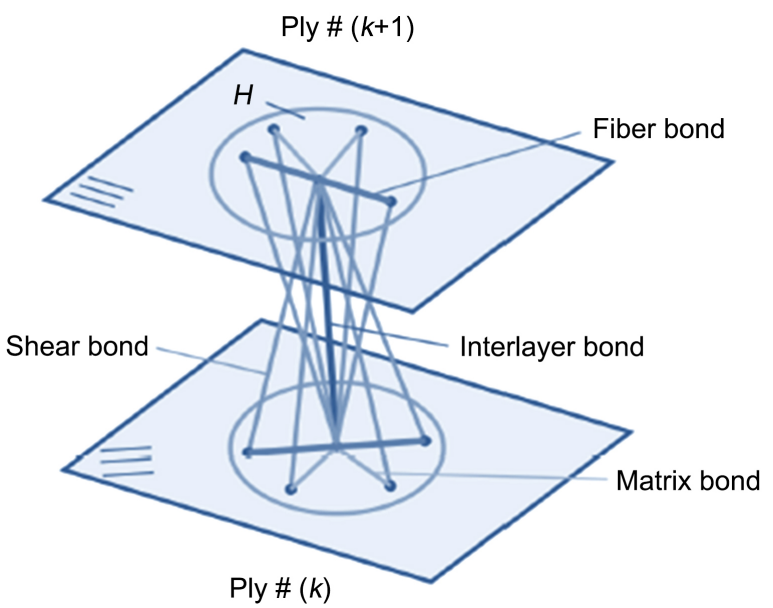

Figure 11. Represents different bonds existing on FRCM. 
It is in this way reasonable for all conceivable cover lay-ups, geometric setups, stacking and limit conditions. Usage of the hypothesis includes deciding tiny strains inside both the polymeric network and fiber periods of composite covers. Naturally visible strains dictated by basic limited component examinations are upgraded by miniaturized scale mechanical strain enhancement elements to assess the real resist the tiny level [32].

The mechanical model which permits the expectation of the conduct of different inhomogeneities in composite materials is furnished by the arrangements of conditions with quickly fluctuating coefficients which portray the properties of the individual periods of the composite material. The subsequent limit esteem issues are fairly intricate, and it is very ordinary, hence, to look for mechanical models with some found the middle value of coefficients [33].

Fiber fortified composite materials are utilized broadly in light of their physicochemical properties and their high quality/weight proportion. The utilization of composites in Army vehicles as a method for diminishing weight and improving survivability, without lessening faculty security, has been considered for quite a while. The U.S. Armed force Materials Technology Laboratory (AMTL) has effectively illustrated, in a prior program, that a ground vehicle could be created from FRC materials, presently the innovation has been applied to the manufacture of a composite vechile. The U.S. Naval force is additionally considering the utilization of FRC materials for various boat and submarine applications including use as major auxiliary parts [34]. High-execution structures are regularly made of unidirectional fiber strengthened plastics (UD-FRPs) because of their high quality and firmness combined with low weight [35]. The application region ranges from athletic gear to airframe structures. The support bearing can preferably be adjusted to a specific pressure state so this sort of material is exceptionally adaptable. For most extreme abuse of material stores, harm and disappointment situations ought to be thought about during the structure stage [36].

The capability of composite materials was first acknowledged by aviation and safeguard ventures. During the previous decades, interest for the composite materials has expanded in an assortment of ventures including aviation, vehicle, marine, common, concoction and natural gear, and sports. Inferable from the adaptable highlights and refined qualities of constituents, composites add to predominant last properties in various applications. Especially fiber fortified composite overlays have gotten one of the most fascinating gatherings of materials, because of their interesting properties, for example, high explicit quality, high explicit firmness, low warm development, great erosion opposition and low weight [37].

\section{Thermal expansion of FRCM}

The complexities of composite materials are because of the obscure highlights, for example, compound similarity, wettability, adsorption qualities and ad- 
vancement of complex pressure states coming about because of contrasts in warm and dampness extension, have so far confined their total portrayal. Understanding the conduct of composites comparative with the properties of fiber and lattice materials is attractive not just for the down to earth motivation behind anticipating the properties of composites yet in addition for the essential information required in growing new materials. Linear warm development is the fragmentary change long of a body when warmed or cooled through a given temperature run and for the most part, it is given as a coefficient for each unit temperature span, either as a normal over an expressed range, or as the digression to the extension bend at a given temperature. These composite properties can be tentatively estimated, which can be costly and tedious while assessing various material frameworks, or anticipated utilizing the warm and mechanical properties of the constituents. Furthermore, because of the expanding PC innovation, numerical arrangements, for example, limited component examination are being utilized to decide the warm development coefficients of composite materials. Moreover, because of the expanding PC innovation, numerical arrangements, for example, limited component investigation is being utilized to decide the warm development coefficients of composite materials [38]. The issue of relating compelling properties of fiber strengthened composite materials to constituent properties has gotten significant consideration. Numerous expository models exist for the forecast of the limits for successful coefficients of warm extension for unidirectional fiber fortified composites with isotropic or anisotropic phases. The numerical multifaceted nature of the examination in the different hypotheses ranges from the basic law of blends to strategies utilizing thermoelastic vitality standards [39].

Disfigurement conduct of carbon fiber-strengthened polymer composites includes systems at various length scales with a solid reliance on the carbon fiber type and quality, fiber measuring, decision of polymer framework, type of fortification, and assembling process. Maritime structures ordinarily utilize sandwich materials including low-thickness froth center materials. Given the huge measure of factors related with materials and preparing techniques, a precise science based structure is required for prescient capacities to show static, weakness, and break conduct and its reliance on seawater and temperature. Utilizing materials of high enthusiasm to US Navy, such a structure is proposed considering T700 carbon strands explicitly estimated for vinylester pitch framework having brominated added substances for improved fire execution. Material composites produced using VARTM process with appropriate post-fix were used all through the trial battle. The sandwich lay-up for this examination comprises of a shut cell polymeric (PVC) froth center set between flimsy carbon fiber-strengthened vinylester facings [40].

Moreover, sunlight based radiation, particularly the Ultraviolet (UV) and noticeable light of sun powered radiation is another an antagonistic ecological specialist to materials. UV and obvious radiation are a piece of sun oriented radia- 
tion and show properties normal for the two waves and particles (additionally called as photon). Truth be told, the sun powered radiation likewise incorporates the infrared range and others, however the vitality of photographs in them is only from time to time adequately incredible to incite the substance responses. The frequency of UV part of sun oriented radiation is in the $290-400 \mathrm{~nm}$ band and the relating vitality of these UV photons is ordinarily $290-460 \mathrm{~kJ} /$ mode which is tantamount to the separation energies of polymer covalent bonds. The retention of UV photographs by polymer or PMC produces the photograph oxidation response which goes with the sub-atomic chain scission or chain cross-connecting and materials disintegration. In the presence of obvious light, the chromophoric synthetic species as a creation of photograph oxidation response may ingest noticeable frequency, trailed by the staining to PMC. For the moderately short introduction to UV radiation, insignificant changes in the surface morphology are watched. In any case, for the long introduction, grid overwhelmed properties can encounter the serious debasement [41].

A sandwich board is a case of the auxiliary composite, which basically includes a consistent inward center and two hardened external skins. The high unbending nature of the board is an aftereffect of collaboration among center and external skins. It discovers application in territories running from aviation to vehicle and reaches out to territories where enormous twisting obstruction is essential. In sandwich development, the basic property of center is to improve the thickness of the sandwich structure without expanding by and large weight. There are different kinds of the centers, similar to froth center, honeycomb center, creased center and bracket center. The honeycomb centers show high anisotropic reaction during the in-plane and out-of-plane squashing [42].

In vertebrates, all together for controlled real development to be conceivable, power produced by the enactment of contractile atoms inside muscle Pbers must be applied onto the hard skeleton of the body. A prst venture of this power transmission process is to permit power to cross the cell film of the muscle cell [43]. Many fiber fortified composite materials offer a blend of solidarity and modulus that is either equivalent to or superior to customary metallic materials. Due to their low densities, the particular quality and explicit modulus of these composite materials might be especially better than those of metallic materials [44]. Furthermore weariness solidarity to weight proportions, just as weakness harm resistance, of numerous composite covers are brilliant. Thus, fiber fortified composites have risen as a significant class of basic material [45].

Wellbeing prerequisites are endorsed for the circuit, the vehicle and the pilot gear. Specifically the vehicles are exposed to various tests, both static and dynamic, to guarantee that the necessary degree of wellbeing execution is accomplished. Every one of these tests is acted in a research facility under controlled conditions and within the sight of a FIA specialized representative. Four sorts of effect are mentioned for the endurance cell: frontal, back, side and guiding segment. All the four sorts of effect include composite structures that assimilate a 
high measure of vitality by methods for a mind boggling mix of crack systems including lattice splitting, delamination and fiber breakage [46]. Fiber-strengthened plastics have progressively broadened their utilization in basic application because of the high explicit quality and directional properties. In spite of the fact that in numerous application composites are restored to conclusive shape, machining can at present be required at both the prepreg and the item arranges. Regular machining tasks are hard to perform because of the anisotropy, inhomogeneous structure, hardness and abrasiveness of composite material. Exorbitant device wear altogether expands the machining time and cost. Laser machining utilizing a powerful thickness shaft offers a few favorable circumstances over regular techniques, for example, zero apparatus wear and contact-power initiated issues [47].

The crack conduct of nanotube-fortified composites is relied upon to be portrayed like their fiber-strengthened composite analogs by the blend of complex microdamage occasions, for example, fiber breakage, interface de-union, framework disappointment, to make reference to a couple. A significant material trademark adding to the multifaceted nature of the disappointment procedure in composites is the disappointment method of every one of the composite constituents, which relies emphatically upon the material microstructure and other significant boundaries, for example, the idea of the fiber/grid interface [48]. Craniofacial bone remaking is chosen to address enormous skull bone deformities emerging from the treatment of tumors, contamination, injury, intracranial discharge, or localized necrosis. These imperfections cause both useful and stylish uneasiness to patients. In instances of intracranial drain or then again dead tissue, these conditions may cause growing of cerebrum tissue and in this manner decompressive craniotomy can be a live-sparing procedure. There is a long history of remaking huge skull bone deformities with autogenous bone and it remains the highest quality level of treatment. An autogenous bone join as a rule reaped from calvarium, iliac peak, tibia, or fibula. During craniotomy, the extricated skull bone fold can likewise fundamentally be taken to the mid-region or cryopreserved. Drawbacks to reproduction are identified with conceivable disease of the bone unite, giver site grimness, and treatment of the bone join, which regularly is tedious [49]. Global showcase is expeditiously moving towards the vitality preservation and vitality decrease process. For the most part, the common strands were regularly used to decrease the heaviness of the segments for example the filaments are strengthened with the appropriate network. In the part of cost, sustainable and biodegradability, the characteristic plant strands have a lot of points of interest when contrast with the engineered fibers. Several creators did their examination in the region of common filaments [50].

\section{Microbial Growth on FRC}

Microorganisms might be answerable for physical and concoction changes in composite materials. Immunization of a parasitic consortium to pre-cleaned 
coupons of five composites brought about profound infiltration into the inside of all materials at a temperature of around $22^{\circ} \mathrm{C}$ inside 5 weeks. None of the live composites tried opposed contagious assault. Vaccination of concentrates of these composites with similar organisms brought about higher development contrasted with the control, proposing that concoction mixes drained from the composites were used by microorganisms as a wellspring of carbon and vitality. Studies with unadulterated strands utilized in the production of composite materials demonstrated that the organisms developed quickly on both glass and carbon filaments within the sight of the parasitic consortium. Composite materials have a two-stage structure, a fiber which goes about as the support, and a sap grid. An enormous number of filaments are contained per unit volume as a method for expanding the quality of the material, since the fiber directs its quality [51] (Figure 12: Microbial growth on composite extracts as a source of carbon and energy after 30 days of incubation).

Models incorporate lightweight, solid and inflexible airplane outlines, composite drive shafts and suspension segments, athletic gear, pressure vessels and rapid flywheels with prevalent vitality stockpiling abilities. A purpose behind the far reaching utilization of covered composite materials is their inalienable tailorability, which empowers them to meet explicit plan targets for a given application. A few strategies have been accounted for in the writing for the enhancement of overlaid composite materials [52]. Recently, another class of composite materials known as practically evaluated materials (FGMs) has drawn extensive consideration. Normally, FGMs are made of a blend of earthenware production and metals and are portrayed by the smooth and persistent variety of properties starting with one surface then onto the next. FGMs are currently produced for the general use as auxiliary parts in high temperature conditions [53]. Fiber-fortified plastics (FRPs) are frequently utilized for superior structures since this material joins high solidness, high quality and low weight. The application

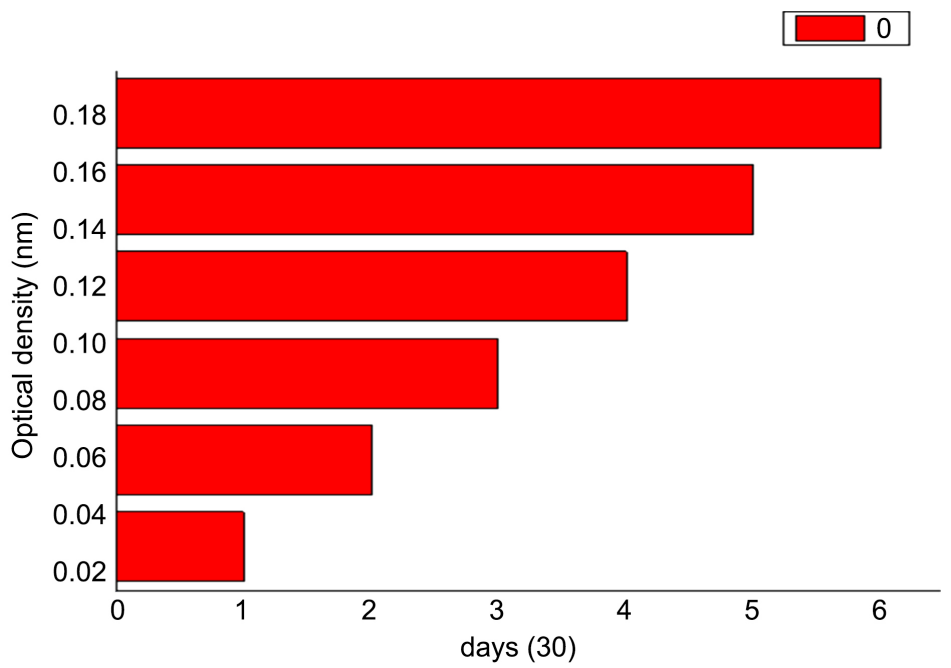

Figure 12. Microbial growth on composite extracts as a source of carbon and energy after 30 days of incubation. 
territory ranges from sports utilities to airframe structures, for example, tennis rackets, bikes, wings or airfoil parts and rotor cutting edges. First endeavors have likewise been made to utilize FRPs for airplane fuselage structures. Composite covers are profoundly adjustable in light of the fact that fiber directions can be adjusted to a specific pressure state. For ideal abuse of material saves, a few break situations ought to be mulled over during the plan stage [54]. Glass fiber-fortified composite materials are significant materials and are utilized in development industry, car and sports merchandise producing, because of the upsides of its mechanical properties. They have high explicit firmness and quality, high damping, great consumption opposition and low warm development [55].

Picking a material reason for high-temperature structure materials experiences a key difficulty. Oxide materials show creep proclivity at high temperatures, restricting their application in vitality offices and the avionic business. Non-oxide materials, which have expanded wet blanket steadiness at high temperatures, are not thermodynamically stable in air and respond with oxygen and additionally moisture. Those which structure defensive oxide layers either contain oxide-type grain limit stages advancing wet blanket and expanded inward oxygen dissemination at higher temperatures or have lower durability esteems [56]. Optimal mechanical execution of glass fiber strengthened epoxy framework composites normally depends on the reasonableness of its interfacial properties to the applied stacking conditions. The differentiating interfacial necessities for glass fiber composites in ballistic versus basic applications require multi-segment structures that lead to an expansion in the framework's weight, cost and multifaceted nature. Along these lines, interfacial alterations that yield a multifunctional composite execution are important to at the same time yield maximal vitality assimilation under unique stacking rates, and high protection from delamination under static stacking rates [57]. Albeit completely inexhaustible asset based materials are all the more ecofriendly, such materials may not fulfill execution characteristics for certain mechanical applications. The polymers and materials got from blended inexhaustible and petroleum product sources not just show solid guarantee in lightening the non-renewable energy source reliance yet in addition have an additional preferred position of conveying the ideal execution from a progressively supportable stock material [58].

Three dimensional (3D) printing is an added substance fabricating procedure to build 3D objects from an advanced model that has gotten a lot of consideration from a differing scope of fields counting electronics, regenerative medicine, aerospace, and microfluidics. Objects are made by consecutively saving endless supply of ink to develop the 3D structure. An preferred position of 3D printing over other added substance creation innovations is that numerous materials can be consolidated into a solitary form. With computerized displaying this element gives the printer spatial control of the material properties inside an item. Slope structures and novel composite materials can be printed by specifically designing diverse inks. These preparing favorable circumstances are especially helpful for 
the development of complex structures where spatially shifting mechanical properties are likely required. An essential case of such a region which uses such characteristics is bioengineering, where printing composites are required to imitate sensible tissues like skin or even organs [59]. High execution carbon fiber strengthened composites with controllable firmness could change the utilization of composite materials in auxiliary applications. Here we depict a auxiliary material, which has a firmness that can be effectively controlled on request. Such a material could have applications in transforming wings or deployable structures. A carbon fiber fortified epoxy composite is depicted that can experience a $88 \%$ decrease in flexural firmness at raised temperatures and completely recuperate when cooled, with no detectable harm or misfortune in properties [60]. When the firmness has been diminished, the necessary miss-happenings can be accomplished at much lower activation powers. For this verification of-idea study, a slim polyacrylamide (PAAm) layer was electro coated onto carbon filaments that were then installed into an epoxy lattice by means of sap mixture [61]. The significant expense and vitality power of virgin carbon fiber make gives a chance to recoup generous incentive from carbon fiber strengthened plastic squanders. In this examination, we survey the existence cycle natural ramifications of recouping carbon fiber and creating composite materials alternative for regular and proposed lightweight materials in car applications (e.g., steel, aluminum, virgin carbon fiber). Key boundaries for the reused carbon fiber materials, including fiber volume part and fiber arrangement, are explored to recognize useful employments of reused carbon fiber in the car area. Reused carbon fiber segments can accomplish the most minimal life cycle ecological effects of all materials considered, in spite of the fact that the genuine effect is exceptionally subject to the structure standards. What's more, reused carbon fiber segments have low being used vitality use because of mass decreases and related decrease in mass-actuated fuel utilization [62].

Engineered polymers are as of now joined with different biodegradable fortifying filaments so as to improve mechanical properties and acquire the attributes requested in real applications. Research is proceeding to supplant manufactured strands with lignocellulosic filaments as reinforcement. Compared to different engineered filaments, the lignocellulosic strands (corn tail, rice husk, palm, coir, jute, abaca, wheat straw, and grass, and so forth.) are lightweight, decline wear in the machine utilized for their creation, and are effectively accessible, inexhaustible, biodegradable, and economical [63]. Crystalline morphology of semicrystalline polymers pronouncedly impacts the mechanical and physical exhibitions, subsequently, it is in fact useful to control the crystalline morphology with the point of propelling the properties and functionalities [64].

Built composite materials have become a significant establishment of a considerable lot of todays' innovations and structures. Of these, fiberglass-fortified composites specifically have found applications in fields like the car and aviation enterprises, which request lightweight materials with a high unbending nature 
and strength. To fulfill the different innovative requests, a balanced and adequate interfacial bond among filaments and resinous grid is of vital significance. Grip to a great extent relies upon sub-atomic interfacial structures and sub-atomic interfacial communications. Thus, fiber surface alteration by coatings has been recognized as a reasonable way impact and control the grip and similarity of the constituent materials [65]. Many organic materials are composites, with models running from the mineral protein composites of issue that remains to be worked out polymer-polymer composites making up the plant cell divider. In spite of the constituent materials regularly having poor properties, Nature figures out how to create mass materials with incredible properties that emerge through stunning control of interfaces between the constituents. It is trusted that a crucial comprehension of interfacial structure in nature will offer ascent to new thoughts for future applications [66].

\section{Crystalline Morphology of FRCM}

Carbon fiber strengthened polymers (CFRP), made of carbon filaments (CFs) fortifying a sap framework, are vital to the creation of more grounded at this point lighter segments for planes, vehicles, trains, transport holders and wind turbines [67]. The consistently expanding necessities for cost productivity and natural arrangements prompted the slow relocation from metallic to composite structures in these ventures, as the decrease in weight, lessens fuel utilization and nursery outflows. The high explicit in planemechanical properties of CFs is the foundation of the predominant exhibition of CFRPs [68]. Lightweight nanocomposites strengthened with carbon nanotube (CNT) congregations raise the possibilities for a scope of cutting edge designing applications. In any case, a relationship between's their heterogeneous compound structure and spatial association of nanotubes ought to be unmistakably comprehended to amplify their exhibition. Here, we actualize the propelled imaging capacities of nuclear power microscopy joined with close field infrared spectroscopy (AFM-IR) to examine the many-sided concoction structure of CNT fiber-fortified thermoset nanocomposites [69].

Crystalline morphology of semicrystalline polymers pronouncedly impacts the mechanical and physical exhibitions, in this manner, it is as a matter of fact productive to control the crystalline morphology with the point of propelling the properties and functionalities [64].

Composite materials made by consolidating two centers more segments accomplish properties, which couldn't be achieved with the different components. Generally, fortifying fillers have a positive effect on mechanical properties and lessen the expense of last products. Currently, different inorganic materials, for example, powder, mud, calcium carbonate and glass fiber are as often as possible used as strengthening fillers in composite materials [70]. Approximately $95 \%$ of composites utilized today are manufactured from glass fibers. Properties of a composite material rely upon the properties of its constituent parts, particularly 
on the collaboration of interfaces between the support and a network. The shape, size, surface movement, and volume division of any filler will impact the last composite properties [71]. Polymer-grid fiber-fortified composites may ingest around 3 percent by weight of water during ecological introduction due, for the most part, to dispersion through the network. The potential impacts of this water on the mechanical properties of the composite are critical [72].

To lessen the general weight and improve the efficiency of vehicles, an ever increasing number of metal parts are being supplanted by polymer composite materials. In opposition to metals, particularly in pressure, most composites are by and large described by a fragile instead of pliable reaction to stack [73]. On the entire, irregular hacked fiber composites are still viewed as moderately new materials in the field and regularly come up short on the gritty material property and execution portrayal that are require before they can be utilized broadly in different applications. Intriguedusers can allude to our work on car crashworthiness where in we have taken a gander at the particular vitality ingestion in a pressure formed arbitrary cleaved carbon fiber [74]. At present, the surgeries used to lighten this condition incorporate circle extraction, chemonucleolysis and spinal combination. While these strategies have a high pace of achievement in reducing side effects, none is without optional issues including narrowing of the circle space and degeneration at contiguous fragments [75].

\section{Conclusion}

Fiber reinforced composite materials will be very useful and reusable technology in every aspect of science and technological fields. Within every short time, we can see the result of FRC in a giant perspective of our life. The most uprising aspect of medical fields with the use FRCM combination especially in surgical purposes and replacement of artificial parts is increasing day by day with significant changes. The novelty of this research is going on. With the use of recycling technology of FRCM, we can minimize waste and which will refer an ecofriendly technology for the world and our nature.

\section{Acknowledgements}

I would to like to be grateful to Mr. Kerstens and Mr. Fuda Ning for their support.

\section{Conflicts of Interest}

The authors declare no conflicts of interest regarding the publication of this paper.

\section{References}

[1] Voyiadjis, G.Z. and Kattan, P.I. (1993) Damage of Fiber-Reinforced Composite Materials with Micromechanical Characterization. International Journal of Solids and Structures, 30, 2757-2778. https://doi.org/10.1016/0020-7683(93)90153-X 
[2] Rahman, M., et al. (1999) Machinability Study of Carbon Fiber Reinforced Composite. Journal of Materials Processing Technology, 89-90, 292-297.

https://doi.org/10.1016/S0924-0136(99)00040-0

[3] Chandrasekharan, V., Kapoor, S.G. and Devor, R.E. (1995) A Mechanistic Approach to Predicting the Cutting Forces in Drilling: with Application to Fiber-Reinforced Composite Materials. Journal of Engineering for Industry, 117, 559-570. https://doi.org/10.1115/1.2803534

[4] Tan, P. and Tong, L. (2001) Micro-Electromechanics Models for Piezoelectric-Fiber-Reinforced Composite Materials. Composites Science and Technology, 61, 759-769. https://doi.org/10.1016/S0266-3538(01)00014-8

[5] Farley, G.L. and Jones, R.M. (1992) Crushing Characteristics of Continuous Fiber-Reinforced Composite Tubes. Journal of Composite Materials, 26, 37-50. https://doi.org/10.1177/002199839202600103

[6] Lin, S.C. and Chen, I.K. (1996) Drilling Carbon Fiber-Reinforced Composite Material at High Speed. Wear, 194, 156-162. https://doi.org/10.1016/0043-1648(95)06831-7

[7] Dyer, S.R., et al. (2005) Effect of Cross-Sectional Design on the Modulus of Elasticity and Toughness of Fiber-Reinforced Composite Materials. The Journal of Prosthetic Dentistry, 94, 219-226. https://doi.org/10.1016/j.prosdent.2005.06.008

[8] Wang, X., et al. (2011) Effects of Interphase Properties in Unidirectional Fiber Reinforced Composite Materials. Materials \& Design, 32, 3486-3492. https://doi.org/10.1016/j.matdes.2011.01.029

[9] Fraternali, F., et al. (2015) A Tensegrity Approach to the Optimal Reinforcement of Masonry Domes and Vaults through Fiber-Reinforced Composite Materials. Composite Structures, 134, 247-254. https://doi.org/10.1016/j.compstruct.2015.08.087

[10] Siddhartha and Gupta, K. (2012) Mechanical and Abrasive Wear Characterization of Bidirectional and Chopped E-Glass Fiber Reinforced Composite Materials. Materials \& Design, 35, 467-479. https://doi.org/10.1016/j.matdes.2011.09.010

[11] Lin, W.-P. and Hu, H.-T. (2002) Nonlinear Analysis of Fiber-Reinforced Composite Laminates Subjected to Uniaxial Tensile Load. Journal of Composite Materials, 36, 1429-1450. https://doi.org/10.1177/0021998302036012463

[12] Lee, J.D. (1980) Three Dimensional Finite Element Analysis of Layered Fiber-Reinforced Composite Materials. Computers \& Structures, 12, 319-339. https://doi.org/10.1016/0045-7949(80)90030-9

[13] Rosner Charles, N. and Rizkalla Sami, H. (1995) Bolted Connections for Fiber-Reinforced Composite Structural Members: Experimental Program. Journal of Materials in Civil Engineering, 7, 223-231. https://doi.org/10.1061/(ASCE)0899-1561(1995)7:4(223)

[14] El Kadi, H. (2006) Modeling the Mechanical Behavior of Fiber-Reinforced Polymeric Composite Materials Using Artificial Neural Networks-A Review. Composite Structures, 73, 1-23. https://doi.org/10.1016/j.compstruct.2005.01.020

[15] Stango, R.J. and Wang, S.S. (1984) Process-Induced Residual Thermal Stresses in Advanced Fiber-Reinforced Composite Laminates. Journal of Engineering for Industry, 106, 48-54. https://doi.org/10.1115/1.3185910

[16] Saravanos, D.A. andLamancusa, J.S. (1990) Optimum Structural Design of Robotic Manipulators with Fiber Reinforced Composite Materials. Computers \& Structures, 36, 119-132. https://doi.org/10.1016/0045-7949(90)90181-Z

[17] Soutis, C. (2005) Carbon Fiber Reinforced Plastics in Aircraft Construction. Mate- 
rials Science and Engineering. A, 412, 171-176. https://doi.org/10.1016/j.msea.2005.08.064

[18] Nokes, J.P. andCloud, G.L. (1993) The Application of Interferometric Techniques to the Nondestructive Inspection of Fiber-Reinforced Materials. Experimental Mechanics, 33, 314-319. https://doi.org/10.1007/BF02322147

[19] Sprenger, S. (2013) Improving Mechanical Properties of Fiber-Reinforced Composites Based on Epoxy Resins Containing Industrial Surface-Modified Silica Nanoparticles: Review and Outlook. Journal of Composite Materials, 49, 53-63. https://doi.org/10.1177/0021998313514260

[20] Kerstens, S., Decraemer, W.F. and Verbelen, J.-P. (2001) Cell Walls at the Plant Surface Behave Mechanically Like Fiber-Reinforced Composite Materials. Plant Physiology, 127, 381-385. https://doi.org/10.1104/pp.010423

[21] Natali, A., Manzi, S. and Bignozzi, M.C. (2011) Novel Fiber-Reinforced Composite Materials Based on Sustainable Geopolymer Matrix. Procedia Engineering, 21, 1124-1131. https://doi.org/10.1016/j.proeng.2011.11.2120

[22] Rahimizadeh, A., et al. (2019) Recycling of Fiberglass Wind Turbine Blades into Reinforced Filaments for Use in Additive Manufacturing. Composites Part B: Engineering, 175, Article ID: 107101.

https://doi.org/10.1016/j.compositesb.2019.107101

[23] Lima, P.R.L., et al. (2018) Short Sisal Fiber Reinforced Recycled Concrete Block for One-Way Precast Concrete Slabs. Construction and Building Materials, 187, 620-634. https://doi.org/10.1016/j.conbuildmat.2018.07.184

[24] Hagnell, M.K. and Åkermo, M. (2019) The Economic and Mechanical Potential of Closed Loop Material Usage and Recycling of Fibre-Reinforced Composite Materials. Journal of Cleaner Production, 223, 957-968.

https://doi.org/10.1016/j.jclepro.2019.03.156

[25] Menges, G. (1994) New Developments in Chemical Recycling as a Sink for Problematic Waste from Fiber-Reinforced Plastics. Journal of Thermoplastic Composite Materials, 7, 64-74. https://doi.org/10.1177/089270579400700106

[26] Dano, M.L. and Hyer, M.W. (2002) Snap-Through of Unsymmetric Fiber-Reinforced Composite Laminates. International Journal of Solids and Structures, 39, 175-198. https://doi.org/10.1016/S0020-7683(01)00074-9

[27] Vallittu, P.K. and Sevelius, C. (2000) Resin-Bonded, Glass Fiber-Reinforced Composite Fixed Partial Dentures: A Clinical Study. The Journal of Prosthetic Dentistry, 84, 413-418. https://doi.org/10.1067/mpr.2000.109782

[28] Fazzino, P. and Reifsnider, K. (2008) Electrochemical Impedance Spectroscopy Detection of Damage in out of Plane Fatigued Fiber Reinforced Composite Materials. Applied Composite Materials, 15, 127-138. https://doi.org/10.1007/s10443-008-9062-6

[29] Hour, K.-Y. and Sehitoglu, H. (1993) Damage Development in a Short Fiber Reinforced Composite. Journal of Composite Materials, 27, 782-805. https://doi.org/10.1177/002199839302700803

[30] Khalili, S.M.R., Mittal, R.K. and Mohammad Panah, N. (2007) Analysis of Fiber Reinforced Composite Plates Subjected to Transverse Impact in the Presence of Initial Stresses. Composite Structures, 77, 263-268.

https://doi.org/10.1016/j.compstruct.2005.08.027

[31] Mathias, P.J., et al. (1989) Solid Particle Erosion of a Graphite-Fiber-Reinforced Bismaleimide Polymer Composite. Wear, 135, 161-169.

https://doi.org/10.1016/0043-1648(89)90103-8 
[32] Tran, T.D., et al. (2012) Micromechanical Modelling for Onset of Distortional Matrix Damage of Fiber Reinforced Composite Materials. Composite Structures, 94, 745-757. https://doi.org/10.1016/j.compstruct.2011.09.009

[33] Kalamkarov, A.L. andKolpakov, A.G. (1996) Design Problems for the Fiber-Reinforced Composite Materials. Composites Part B: Engineering, 27, 485-492. https://doi.org/10.1016/1359-8368(96)00029-7

[34] Macaione, D.P. and Tewarson, A. (1990) Flammability Characteristics of Fiber-Reinforced Composite Materials. In: Nelson, G.L., Ed., Fire and Polymers, American Chemical Society, Washington DC, 542-565. https://doi.org/10.1021/bk-1990-0425.ch032

[35] Taya, M. (1981) On Stiffness and Strength of an Aligned Short-Fiber Reinforced Composite Containing Penny-Shaped Cracks in the Matrix. Journal of Composite Materials, 15, 198-210. https://doi.org/10.1177/002199838101500301

[36] Balzani, C. and Wagner, W. (2008) An Interface Element for the Simulation of Delamination in Unidirectional Fiber-Reinforced Composite Laminates. Engineering Fracture Mechanics, 75, 2597-2615.

https://doi.org/10.1016/j.engfracmech.2007.03.013

[37] Isbilir, O. and Ghassemieh, E. (2013) Numerical Investigation of the Effects of Drill Geometry on Drilling Induced Delamination of Carbon Fiber Reinforced Composites. Composite Structures, 105, 126-133. https://doi.org/10.1016/j.compstruct.2013.04.026

[38] Oshima, A., Udagawa, A. and Morita, Y. (2001) Application of Radiation-Crosslinked Polytetrafluoroethylene to Fiber-Reinforced Composite Materials. Radiation Physics and Chemistry, 60, 467-471. https://doi.org/10.1016/S0969-806X(00)00416-3

[39] Karadeniz, Z.H. and Kumlutas, D. (2007) A Numerical Study on the Coefficients of Thermal Expansion of Fiber Reinforced Composite Materials. Composite Structures, 78, 1-10. https://doi.org/10.1016/j.compstruct.2005.11.034

[40] Penumadu, D. (2018) Durability of US Naval Composites and Sandwich Structures: Science Framework Considering Multiscale Response in Harsh Sea Environment. In: Davies, P. and Rajapakse, Y., Eds., Durability of Composites in a Marine Environment 2, Solid Mechanics and Its Applications, Springer, Cham, 59-74. https://doi.org/10.1007/978-3-319-65145-3_4

[41] Ding, A., et al. (2018) Ageing of Sandwich Composites with E-Glass Fibre/Vinylester Skins and PVC Foam Core in Synergistic Environmental Agents. Composite Structures, 202, 253-260. https://doi.org/10.1016/j.compstruct.2018.01.071

[42] Sahu, S.K., et al. (2018) Influence of Cell Size on out of Plane Stiffness and In-Plane Compliance Character of the Sandwich Beam Made with Tunable PCTPE Nylon Honeycomb Core and Hybrid Polymer Nanocomposite Skin. International Journal of Mechanical Sciences, 148, 284-292. https://doi.org/10.1016/j.ijmecsci.2018.08.011

[43] Huijing, P.A. (1999) Muscle as a Collagen Fiber Reinforced Composite: A Review of Force Transmission in Muscle and Whole Limb. Journal of Biomechanics, 32, 329-345. https://doi.org/10.1016/S0021-9290(98)00186-9

[44] Khot, N.S., et al. (1973) Optimization of Fiber Reinforced Composite Structures. International Journal of Solids and Structures, 9, 1225-1236. https://doi.org/10.1016/0020-7683(73)90113-3

[45] Yuanjian, T. and Isaac, D.H. (2008) Combined Impact and Fatigue of Glass Fiber Reinforced Composites. Composites Part B: Engineering, 39, 505-512. https://doi.org/10.1016/j.compositesb.2007.03.005 
[46] Bisagni, C., et al. (2005) Progressive Crushing of Fiber-Reinforced Composite Structural Components of a Formula One Racing Car. Composite Structures, 68, 491-503. https://doi.org/10.1016/j.compstruct.2004.04.015

[47] Pan, C.T. and Hocheng, H. (1996) The Anisotropic Heat-Affected Zone in the Laser Grooving of Fiber-Reinforced Composite Material. Journal of Materials Processing Technology, 62, 54-60. https://doi.org/10.1016/0924-0136(95)02192-2

[48] Lourie, O. and Wagner, H.D. (1999) Evidence of Stress Transfer and Formation of Fracture Clusters in Carbon Nanotube-Based Composites. Composites Science and Technology, 59, 975-977. https://doi.org/10.1016/S0266-3538(98)00148-1

[49] Aitasalo, K.M.J., et al. (2014) Craniofacial Bone Reconstruction with Bioactive Fiber-Reinforced Composite Implant. Head \& Neck, 36, 722-728.

https://doi.org/10.1002/hed.23370

[50] Sathishkumar, T.P., Navaneethakrishnan, P. and Shankar, S. (2012) Tensile and Flexural Properties of Snake Grass Natural Fiber Reinforced Isophthallic Polyester Composites. Composites Science and Technology, 72, 1183-1190.

https://doi.org/10.1016/j.compscitech.2012.04.001

[51] Gu, J.-D., et al. (1996) Microbial Growth on Fiber Reinforced Composite Materials. International Biodeterioration \& Biodegradation, 37, 197-204.

[52] Pelletier, J.L. and Vel, S.S. (2006) Multi-Objective Optimization of Fiber Reinforced Composite Laminates for Strength, Stiffness and Minimal Mass. Computers \& Structures, 84, 2065-2080. https://doi.org/10.1016/j.compstruc.2006.06.001

[53] Xia, X.-K. andShen, H.-S. (2009) Nonlinear Vibration and Dynamic Response of FGM Plates with Piezoelectric Fiber Reinforced Composite Actuators. Composite Structures, 90, 254-262. https://doi.org/10.1016/j.compstruct.2009.03.018

[54] Wagner, W. and Balzani, C. (2008) Simulation of Delamination in Stringer Stiffened Fiber-Reinforced Composite Shells. Computers \& Structures, 86, 930-939.

https://doi.org/10.1016/j.compstruc.2007.04.018

[55] Latha, B., Senthilkumar, V.S. and Palanikumar, K. (2011) Modeling and Optimization of Process Parameters for Delamination in Drilling Glass Fiber Reinforced Plastic (GFRP) Composites. Machining Science and Technology, 15, 172-191. https://doi.org/10.1080/10910344.2011.579802

[56] Weinmann, M., et al. (2000) Design of Polymeric Si-B-C-N Ceramic Precursors for Application in Fiber-Reinforced Composite Materials. Chemistry of Materials, 12, 2112-2122. https://doi.org/10.1021/cm001031w

[57] Nasser, J., Steinke, K. and Sodano, H. (2020) ZnO Nanostructured Interphase for Multifunctional and Lightweight Glass Fiber Reinforced Composite Materials under Various Loading Conditions. ACS Applied Nano Materials, 3, 1363-1372. https://doi.org/10.1021/acsanm.9b02216

[58] Bakarich, S.E., et al. (2014) Three-Dimensional Printing Fiber Reinforced Hydrogel Composites. ACS Applied Materials \& Interfaces, 6, 15998-16006.

https://doi.org/10.1021/am503878d

[59] Liu, W., et al. (2005) Injection Molded Glass Fiber Reinforced Poly(Trimethylene Terephthalate) Composites: Fabrication and Properties Evaluation. Industrial \& Engineering Chemistry Research, 44, 857-862. https://doi.org/10.1021/ie049112f

[60] Yoshida, H. (1980) Viscoelastic Properties of Fiber-Reinforced Plastic. In: May, C.A., Ed., Resins for Aerospace, American Chemical Society, Washington DC, 247-256. https://doi.org/10.1021/bk-1980-0132.ch019

[61] Tridech, C., et al. (2013) High Performance Composites with Active Stiffness Control. ACS Applied Materials \& Interfaces, 5, 9111-9119. 
https://doi.org/10.1021/am402495n

[62] Meng, F., et al. (2017) Environmental Aspects of Use of Recycled Carbon Fiber Composites in Automotive Applications. Environmental Science \& Technology, 51, 12727-12736. https://doi.org/10.1021/acs.est.7b04069

[63] Haque, M.M., et al. (2012) Chemical Treatment of Coir Fiber Reinforced Polypropylene Composites. Industrial \& Engineering Chemistry Research, 51, 3958-3965. https://doi.org/10.1021/ie200693v

[64] Xu, H., et al. (2014) Structural Basis for Unique Hierarchical Cylindrites Induced by Ultrahigh Shear Gradient in Single Natural Fiber Reinforced Poly(Lactic Acid) Green Composites. Biomacromolecules, 15, 1676-1686. https://doi.org/10.1021/bm500100z

[65] Chen, C., Curliss, D. and Rice, B.P. (2005) Nanocomposite Aerospace Resins for Carbon Fiber-Reinforced Composites. In: Miziolek, A.W., Karna, S.P., Matthew Mauro, J. and Vaia, R.A., Eds., Defense Applications of Nanomaterials, American Chemical Society, Washington DC, 102-118.

https://doi.org/10.1021/bk-2005-0891.ch007

[66] Kuttner, C., et al. (2013) Influence of the Polymeric Interphase Design on the Interfacial Properties of (Fiber-Reinforced) Composites. ACS Applied Materials \& Interfaces, 5, 2469-2478. https://doi.org/10.1021/am302694h

[67] Haris, G. (2015) COMPETITIVENESS Federal Dollars Help Launch \$250 Million Composites Research Hub. Chemical \& Engineering News Archive, 93, 7.

https://doi.org/10.1021/cen-09303-notw7

[68] Karakassides, A., et al. (2020) Radially Grown Graphene Nanoflakes on Carbon Fibers as Reinforcing Interface for Polymer Composites. ACS Applied Nano Materials, 3, 2402-2413. https://doi.org/10.1021/acsanm.9b02536

[69] Mikhalchan, A., et al. (2018) Revealing Chemical Heterogeneity of CNT Fiber Nanocomposites via Nanoscale Chemical Imaging. Chemistry of Materials, 30, 1856-1864. https://doi.org/10.1021/acs.chemmater.7b04065

[70] Wetherhold, R.C. and Whitney, J.M. (1981) Tensile Failure of Notched Fiber-Reinforced Composite Materials. Polymer Composites, 2, 112-115. https://doi.org/10.1002/pc.750020306

[71] Prokůpek, L., et al. (2011) Sulphur-Vulcanized Polybutadiene as a Matrix in Glass Fiber-Reinforced Composite Materials. Journal of Applied Polymer Science, 119, 3446-3452. https://doi.org/10.1002/app.33042

[72] Thomson, K.W. and Broutman, L.J. (1982) The Effect of Water on the Fracture Surface Energy of Fiber-Reinforced Composite Materials. Polymer Composites, 3, 113-117. https://doi.org/10.1002/pc.750030303

[73] Dilandro, L., Dibenedetto, A.T. and Groeger, J. (1988) the Effect of Fiber-Matrix Stress Transfer on the Strength of Fiber-Reinforced Composite Materials. Polymer Composites, 9, 209-221. https://doi.org/10.1002/pc.750090308

[74] Jacob, G.C., et al. (2006) Fracture Toughness in Random-Chopped Fiber-Reinforced Composites and Their Strain Rate Dependence. Journal of Applied Polymer Science, 100, 695-701. https://doi.org/10.1002/app.23414

[75] Langrana, N.A., et al. (1994) Materials and Design Concepts for an Intervertebral Disc Spacer. I. Fiber-Reinforced Composite Design. Journal of Applied Biomaterials, 5, 125-132. https://doi.org/10.1002/jab.770050205 